\title{
Influence of thermodynamic soil and vegetation parameterizations on the simulation of soil temperature states and surface fluxes by the Noah LSM over a Tibetan plateau site
}

\author{
R. van der Velde ${ }^{1}$, Z. Su ${ }^{1}$, M. Ek ${ }^{2}$, M. Rodell ${ }^{3}$, and Y. $\mathbf{M a}^{4}$ \\ ${ }^{1}$ International Institute for Geo-Information Science and Earth Observation (ITC), Hengelosestraat 99, P.O. Box 6, 7500 AA \\ Enschede, The Netherlands \\ ${ }^{2}$ Environmental Modeling Center, National Center for Environmental Prediction, Suitland, Maryland, USA \\ ${ }^{3}$ Hydrological Science Branch, Code 614.3, NASA, Goddard Space Flight Center, Greenbelt, Maryland, USA \\ ${ }^{4}$ Institute of Tibetan Plateau Research (ITP/CAS), P.O. Box 2871, Beijing 100085, China
}

Received: 21 November 2008 - Published in Hydrol. Earth Syst. Sci. Discuss.: 21 January 2009

Revised: 8 May 2009 - Accepted: 22 May 2009 - Published: 12 June 2009

\begin{abstract}
In this paper, we investigate the ability of the Noah Land Surface Model (LSM) to simulate temperature states in the soil profile and surface fluxes measured during a 7-day dry period at a micrometeorological station on the Tibetan Plateau. Adjustments in soil and vegetation parameterizations required to ameliorate the Noah simulation on these two aspects are presented, which include: (1) differentiating the soil thermal properties of top- and subsoils, (2) investigation of the different numerical soil discretizations and (3) calibration of the parameters utilized to describe the transpiration dynamics of the Plateau vegetation. Through the adjustments in the parameterization of the soil thermal properties (STP) simulation of the soil heat transfer is improved, which results in a reduction of Root Mean Squared Differences (RMSD's) by $14 \%, 18 \%$ and $49 \%$ between measured and simulated skin, $5-\mathrm{cm}$ and $25-\mathrm{cm}$ soil temperatures, respectively. Further, decreasing the minimum stomatal resistance $\left(R_{c, \text { min }}\right)$ and the optimum temperature for transpiration $\left(T_{\mathrm{opt}}\right)$ of the vegetation parameterization reduces RMSD's between measured and simulated energy balance components by $30 \%$, $20 \%$ and $5 \%$ for the sensible, latent and soil heat flux, respectively.
\end{abstract}

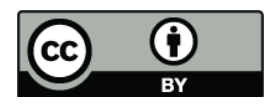

Correspondence to: R. van der Velde (velde@itc.nl)

\section{Introduction}

An accurate characterization of the heat and moisture exchange between the land surface and atmosphere is important for Atmospheric General Circulation Models (AGCM) to forecast weather at various time scales (i.e. McCumber and Pielke, 1981; Garratt, 1993; Koster et al., 2004). Within operational AGCM these land-atmosphere interactions are described by a Land Surface Model (LSM). Because AGCM are computationally demanding, numerical efficiency of the LSM is required. Therefore, a simplified implementation of the physical processes and the applied parameterizations are inevitable. For example, the impact of a physically based formulation of roughness lengths for momentum and heat transport on the calculation of the surface fluxes has been stressed (i.e. Chen et al., 1997; Zeng and Dickinson, 1998; Su et al., 2001; Liu et al., 2007; Ma et al., 2008) and the influence of a more detailed description of the land surface hydrology has been discussed (i.e. Gutmann and Small, 2007; Gulden et al., 2007). Furthermore, a limited number of soil and vegetation parameterizations are accommodated in modeling systems operational at a global scale (e.g. Ek et al., 2003).

The impact of those (and other) uncertainties in the simulation of land processes on the output of an AGCM was evaluated by Dickinson et al. (2006). They found significant differences between measured and simulated precipitation amounts and air temperatures for selected extreme environments, such as the Sahara desert, the semi-arid Sahel, Amazonian rain forest and Tibetan Plateau. These findings are supported by the results presented in Hogue et al. (2005),

Published by Copernicus Publications on behalf of the European Geosciences Union. 
which showed that thorough optimization of a comprehensive set of model parameters, can reduce differences between the measured and simulated heat fluxes for the semiarid Walnut Gulch watershed (Arizona, USA) by as much as $20-40 \mathrm{~W} \mathrm{~m}^{-2}$. The investigation by Dickinson et al. (2006) demonstrates the existence of inconsistencies in the simulations of land surface processes, while Hogue et al. (2005) show that through adjustment of the LSM parameterizations an improvement is obtained in the model's performance. This suggests that even for extreme environment the implemented LSM physics is flexible enough to represent the land surface processes adequately given the appropriate parameterization.

Within the framework of the Model Parameter Estimation Experiment (MOPEX) the development of area specific land surface parameterization has been accommodated (Schaake et al., 2006). The focus of this initiative has been on the development parameter estimation methodologies and the calibration of parameters that affect primarily the rainfall-runoff relationships (Duan et al., 2006). As a result, the influence of model parameters on simulation of surface energy balance has received little attention within MOPEX. One of the few investigations that addressed the impact parameter uncertainty on energy balance simulations has been reported by Kahan et al. (2006). They showed for the Simplified Simple Biosphere (SSiB, Xue et al., 1991) model that adjustment in the Leaf Area Index (LAI), stomatal resistance and saturated hydraulic conductivity ( $\left.K_{\text {sat }}\right)$ are required to decrease systematic differences between simulated and measured sensible and latent heat fluxes for a Sahelian study area in Niger. Moreover, the importance of proper thermal diffusivity is emphasized in order to reduce uncertainties in the simulated diurnal evolution of the surface temperature and sensible heat flux. In a MOPEX-related study, Yang et al. (2005) have shown for the Tibetan Plateau that also the vertical soil heterogeneity may have a significant impact on the partitioning of radiation.

These previous investigations demonstrate that adjustments in soil and vegetation parameterizations can yield significant improvements in the simulation of the surface energy balance. They also emphasize the need to analyze parameter uncertainties of different LSM's in more detail. In this context, the Noah LSM is employed to simulate the land surface process of a Tibetan Plateau site for a 7-day dry period (3 September to 10 September 2005) during the Asian Monsoon. The objective of this study is to identify the adjustments in soil and vegetation parameterizations needed to reconstruct the temperature states in the soil profile and the measured surface energy fluxes over this short period. In this paper, firstly, the results of Noah simulations obtained by using standard parameterizations employed for application at global scales are presented. Secondly, the adjustments in the soil and vegetation parameterizations are explored to optimize the model performance.

\section{Data set}

\subsection{Study site}

The study site selected for this investigation is the micro-meteorological Naqu station located $\left(31.3686^{\circ} \mathrm{N}\right.$, $91.8987^{\circ} \mathrm{E}$ ) approximately $25 \mathrm{~km}$ southwest of Naqu city. This station is part of the meso-scale observational network previously installed in the Naqu river basin in the framework of the GAME (GEWEX (Global Energy and Water cycle Experiment) Asian Monsoon Experiment) and CAMP (CEOP (Coordinated Enhanced Observing Period) Asia-Australia Monsoon Project) Tibet field campaigns. The heat flux measurements collected during these field campaigns have been extensively used to improve the understanding on the water and energy exchange between the land surface and atmosphere over the Tibetan Plateau (e.g. Ma et al., 2002, 2005; Yang et al., 2005, 2008).

In Fig. 1 a subset of a LandSat TM false color image is shown covering a part of the watershed and indicating the location of the study site. Despite the high overall altitude $(4500 \mathrm{~m})$ and significant relief in some parts of this region, the terrain in the proximity of the study site is relatively smooth, varying only tens of meters in elevation. The weather on this part of the plateau is influenced by the warm wet monsoon in the summer and cold dry winters with temperatures below freezing point. Land cover consists of short prairie grasses in higher parts of the watershed and short wetland vegetation in the local depressions. The direct environment of Naqu station consists of short grasses, but within a hundred meters a wetland is situated. Based on textural and hydraulic characterizations performed in the laboratory, the soils can be classified as sandy loam (70\% sand and $10 \%$ silt) with a high saturated hydraulic conductivity $\left(K_{\mathrm{sat}}=1.2 \mathrm{~m} \mathrm{~d}^{-1}\right)$ on top of an impermeable rock formation. Due to the high root density from the short grasses, organic matter content in the top-soils is relatively high (14.2\%).

At Naqu station, instrumentation has been installed to measure atmospheric variables at different levels (e.g. wind speed, humidity and temperature), incoming and outgoing (shortwave and longwave) radiation, turbulent heat fluxes, soil moisture at depths of 5 and $20 \mathrm{~cm}$, and temperatures in the soil profile up to a depth of $40 \mathrm{~cm}$. All variables are recorded at 10-min intervals and a list of the variables used, here, is given in Table 1. From the data record of Naqu station only a 7-day period from 3 to 10 September 2005 has been selected for this investigation. This short period has been selected because the measured rainfall amounts were found to be unreliable due to mechanical difficulties with the logging system and the tipping mechanism of the rain gauge. Since rainfall is such a crucial forcing variable, the period between 3 and 10 September 2005 is used; being the longest summer period without precipitation based on available soil moisture and incoming shortwave radiation measurements. Although the selected period is identified as 


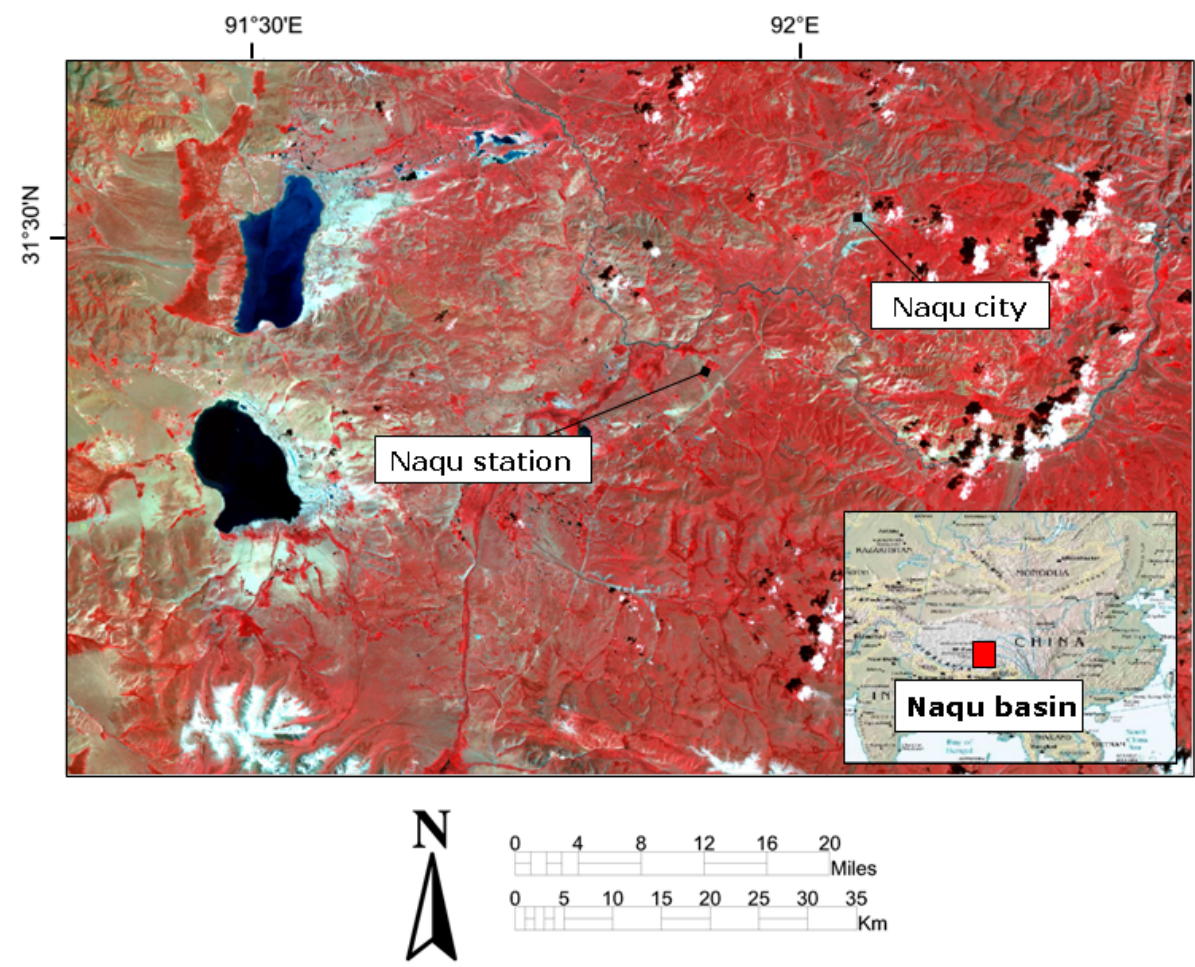

Fig. 1. LandSat TM false color image acquired over the Tibetan study site and its approximate location within the Tibetan Plateau.

completely dry, the soil moisture measurements indicate that prior to 3 September several intensive rain events wetted the land surface. The selected period represents, thus, a typical dry-down cycle, which is, in general, a solid basis for validation of LSM parameterizations.

\subsection{Surface fluxes}

The soil heat flux is reconstructed using Fourier's Law from temperature gradient measurements between the surface $\left(T_{\text {skin }}\right)$ and the soil depth at which the first temperature measurements are made, which is $0.05 \mathrm{~m}\left(T_{5 \mathrm{~cm}}\right)$. This temperature gradient and $G_{0}$ are related to each other as follows,

$G_{0}=\kappa_{h}(s m) \frac{\partial T}{\partial z}=\kappa_{h}(s m) \frac{T_{\text {skin }}-T_{s 1}}{d z}$

where $\kappa_{h}$ is the thermal conductivity $\left[\mathrm{W} \mathrm{m}^{-1} \mathrm{~K}^{-1}\right]$, sm is soil moisture content $\left[\mathrm{m}^{3} \mathrm{~m}^{-3}\right], z$ is the soil depth. Application of this approach requires formulation of the thermal conductivity, which depends on the soil constituents, such as quartz and organic matter contents. Various scientists (e.g. de Vries, 1963; Johansen, 1975; Peters-Lidard et al., 1998) have developed generic formulations to relate the soil texture to the thermal conductivity. In Hillel (1998), however, it is pointed out that $\kappa_{h}$ not merely depends on the soil constituents, but is also affected by the size, shape and spatial arrangement of soil particles. Given the rather specific conditions on the Tibetan Plateau, $\kappa_{h}$ under the initial soil moisture conditions $\left(\kappa_{h}^{i}\right)$ of the analyzed period is derived from the measured soil heat flux at a soil depth of $10 \mathrm{~cm}\left(G_{10}\right)$ and the soil temperature gradient. Using the $\kappa_{h}^{i}$, the $\kappa_{h}$ is extrapolated for following time steps using the measured soil moisture according to,

$\kappa_{h}(s m)=\kappa_{h}^{i}+\left(s m_{i}-s m\right) \kappa_{w}$

where, $\kappa_{w}$ is the thermal conductivity of water $\left[=0.57 \mathrm{~W} \mathrm{~m}^{-1} \mathrm{~K}^{-1}\right]$, and sub- and superscript $i$ refer to the initial conditions of the selected period.

Unfortunately, the turbulent heat fluxes measured by the eddy correlation (EC) instrumentation at Naqu station are not available for the selected period. Therefore, the sensible $(H)$ and latent heat $(\lambda E)$ fluxes have been computed using the Bowen Ratio Energy Balance (BREB) - method (i.e. Perez et al., 1999; Pauwels and Samson, 2006), whereby the Bowen Ratio $(\beta)$ is defined as,

$\beta=\frac{H}{\lambda E}=\gamma \frac{T_{\text {air } 1}-T_{\text {air } 2}}{e_{\text {air } 1}-e_{\text {air } 2}}$

where, $e$ is vapor pressure $[\mathrm{kPa}]$, subscripts air 1 and air 2 indicate the first and second atmospheric level, respectively, and $\gamma$ is psychrometric constant $\left[\mathrm{kPa} \mathrm{K}^{-1}\right]$ defined as,

$\gamma=\frac{c_{p} P}{0.622 \cdot \lambda}$

where, $c_{p}$ is specific heat capacity of moist air $\left[=1005 \mathrm{~kJ} \mathrm{~kg}^{-1} \mathrm{~K}^{1}\right], \quad P$ is the air pressure $[\mathrm{kPa}]$ and $\lambda$ is the latent heat of vaporization $\left[=2.5 \cdot 10^{6} \mathrm{~J} \mathrm{~kg}^{-1}\right]$. 
Table 1. List of measurements conducted at Naqu station at 10-min intervals that have been used in this investigation.

\begin{tabular}{|c|c|c|c|}
\hline Variables & Instrumentation & height [m] & Measurement uncertainty \\
\hline Air pressure & PTB220C, Vaisala & $+1.5 \mathrm{~m}$ & $\pm 1 \mathrm{hPa}$ \\
\hline $\begin{array}{l}\text { Incoming and outgoing, } \\
\text { longwave and } \\
\text { shortwave radiation }\end{array}$ & CM21, Kipp \& Zonen & $+2.0 \mathrm{~m}$ & $\pm 0.5 \%$ at $20^{\circ} \mathrm{C}$ \\
\hline Wind speed & WS-D32, Komatsu & $+1.0 \mathrm{~m},+5.0 \mathrm{~m},+8.2 \mathrm{~m}$ & $\begin{array}{l} \pm 0.8 \mathrm{~m} / \mathrm{s} u<10 \mathrm{~m} / \mathrm{s} \\
\pm 5 \% u>10 \mathrm{~m} / \mathrm{s}\end{array}$ \\
\hline Humidity & HMP-45D, Vaisala & $+1.0 \mathrm{~m},+8.2 \mathrm{~m}$ & $\pm 3 \%$ \\
\hline Air temperature & TS-801(Pt100), Okazaki & $+1.0 \mathrm{~m},+8.2 \mathrm{~m}$ & $\pm 3 \%$ \\
\hline Soil heat flux & MF-81,EKO & $-0.10 \mathrm{~m}$ & $\pm 5 \%$ \\
\hline Soil temperature & Pt100, Vaisala & $\begin{array}{l}\text { Surface, }-0.05 \mathrm{~m},-0.10 \mathrm{~m}, \\
-0.20 \mathrm{~m},-0.40 \mathrm{~m}\end{array}$ & $\pm 0.5^{\circ} \mathrm{C}$ \\
\hline Soil moisture & $10 \mathrm{~cm}$ ECH2O probe, decagon devices & $-0.05 \mathrm{~m},-0.20 \mathrm{~m}$ & $0.024 \mathrm{~cm}^{3} \mathrm{~cm}^{-3}$ \\
\hline
\end{tabular}

Once the $\beta$ has been determined from the air temperature and vapor pressure profiles measurements the $\lambda E$ and $H$ can be calculated using,

$\lambda E=\frac{R_{n}-G_{0}}{1+\beta}$

and

$H=\frac{\beta}{1+\beta}\left(R_{n}-G_{0}\right)$

The $\beta$ has been computed using the air temperature and vapor pressure measurements at levels of $1.0 \mathrm{~m}$ and $8.2 \mathrm{~m}$. As BREB-method has a limited validity when $\beta$ approaches -1.0 , latent and sensible heat fluxes derived from $\beta$ values between -1.3 and -0.7 have been omitted from the data analysis (e.g. Perez et al., 1999; Pauwels et al., 2008).

Since the reliability of BREB-method depends on the accuracy of the measured air temperature and humidity profile, the validity of its application to the Tibetan measurements is evaluated through comparison of the BREB-method and the measured EC heat fluxes, which are both available for the period between 16 April and 26 April 2005. Figure 2 presents the BREB-method fluxes plotted against the EC measurements. The figure shows, despite a large scatter, that the general pattern of data points follows the 1:1 line resulting in a Root Mean Squared Difference (RMSD) of $31.14 \mathrm{~W} \mathrm{~m}^{-2}$. A similar agreement between the BREB-method and EC heat fluxes has previously been reported by Pauwels and Samson (2006). We, therefore, conclude that the BREB-method derived heat fluxes are representative for the EC measurement and can be used to evaluate Noah's performance.

\section{Noah LSM}

The Noah LSM originates from the Oregon State University (OSU) LSM, which includes a diurnally dependent Penman approach for the calculation of the latent heat flux under non-restrictive soil moisture conditions (Marht and Ek, 1984), a simple canopy model (Pan and Marht, 1987), a fourlayer soil model (Marht and Pan, 1984; Schaake et al., 1996) and a Reynolds number based approach for the determination of the ratio between the roughness lengths for momentum and heat transport (Zilintinkevich, 1995; Chen et al., 1997). Since the National Centers for Environmental Prediction (NCEP) started to use the OSU LSM in their AGCM systems, the original OSU model was gradually expanded to be representative for a broader range of surface conditions and was renamed Noah. An overview of the latest changes to Noah is documented in Ek et al. (2003), which affect the cold-season processes most notably (e.g. frozen soil moisture, snow pack process). Also, the recent versions of Noah continue to perform well in various LSM intercomparison studies (e.g., IGPO 2002; Mitchell et al., 2004; Rodell et al., 2004; Kato et al., 2007).

\subsection{Soil water movement}

The soil water flow is simulated through application of the diffusivity form of Richards' equation, which can be formulated as follows,

$$
\frac{\partial s m}{\partial t}=\frac{\partial}{\partial z}\left(D(s m) \frac{\partial s m}{\partial z}\right)+\frac{\partial K(s m)}{\partial z}+S(s m)
$$



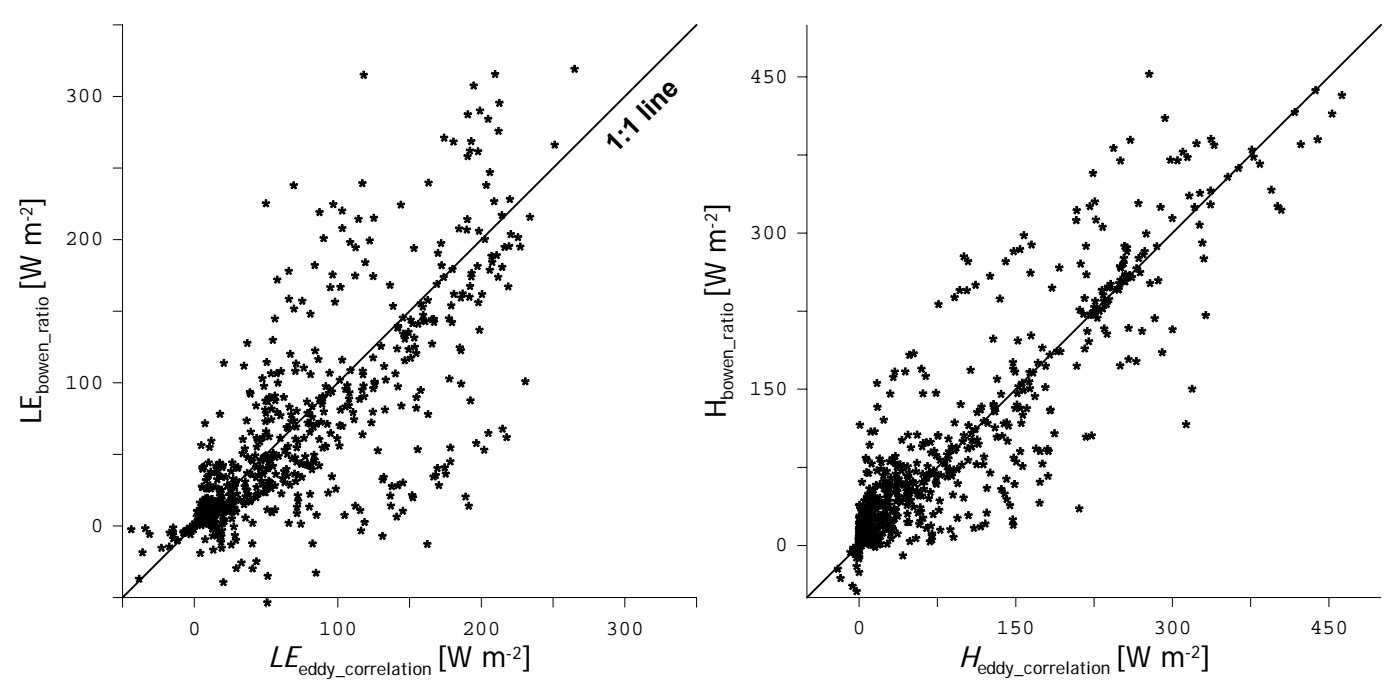

Fig. 2. Comparison of the heat fluxes derived using the Bowen Ratio Energy Balance (BREB) method and from eddy correlation (EC) measurements for the period 16 April and 26 April 2005; the latent heat flux is shown in the left panel and the sensible heat flux in the right panel. The Root Mean Squared difference between the BREB and EC heat fluxes is found to be $31.14 \mathrm{~W} \mathrm{~m}^{-2}$.

where $K$ is the hydraulic conductivity $\left[\mathrm{m} \mathrm{s}^{-1}\right], D$ is the soil water diffusivity $\left[\mathrm{m}^{2} \mathrm{~s}^{-1}\right], S$ is representative for sinks and sources (i.e. rainfall, dew, evaporation and transpiration) $\left[\mathrm{m}^{3} \mathrm{~m}^{-3} \mathrm{~s}^{-1}\right]$, and $t$ represents the time [s]. The non-linear $K$-sm and $D$-sm relationships are defined by the formulation of Cosby et al. (1984) for 9 different soil types.

\subsection{Soil heat flow}

The transfer of heat through the soil column is governed by the thermal diffusion equation,

$C(s m) \frac{\partial T}{\partial t}=\frac{\partial}{\partial z}\left(\kappa_{h}(s m) \frac{\partial T}{\partial z}\right)$

where $C$ is the soil moisture dependent thermal heat capacity $\left[\mathrm{J} \mathrm{m}^{-3} \mathrm{~K}^{-1}\right]$, which is computed using (McCumber and Pielke, 1981),

$C=f_{\text {soil }} C_{\text {soil }}+f_{w} C_{w}+f_{\text {air }} C_{\text {air }}$

where $f$ is the volume fraction of the soil matrix, and subscripts "soil", "w", "air" refer to the solid soil, water and air components. In Noah, $C_{\text {soil }}, C_{\text {air }}$ and $C_{w}$ are defined as $2.0 \cdot 10^{6}, 1005$ and $4.2 \cdot 10^{6} \mathrm{~J} \mathrm{~m}^{-3} \mathrm{~K}^{-1}$, respectively. In reality, $C_{\text {soil }}$ depends also on the soil textural properties, but differences in the heat capacity of the soil constituents can typically be assumed to be negligible (Hillel, 1998) and are, therefore, not accounted for by Noah. For the Tibetan Plateau region, however, Yang et al. (2005) concluded that the presence of roots in the top soil may alter the soil thermal properties (STP) significantly.

The layer integrated form of Eq. (8) is solved using a Crank-Nicholson scheme and the temperature at the bottom boundary is defined as the annual mean surface air temperature, which is specified at a depth of $8 \mathrm{~m}$. Here, for our Tibetan study site a value of $277.25 \mathrm{~K}$ is used. The top boundary condition is confined by surface temperature, which is computed using the surface energy balance. For the calculation of the surface temperature the following linearization is employed,

$T_{\text {skin }}^{4} \approx T_{\text {air }}^{4}\left[1+4\left(\frac{T_{\text {skin }}-T_{\text {air }}}{T_{\text {air }}}\right)\right]$

Substitution of Eq. (10) into the energy balance equation yields the following expression for the surface temperature,

$T_{\text {skin }}=T_{\text {air }}+\frac{F-H-\lambda E-G_{0}}{4 T_{\text {air }}^{3}}-\frac{1}{4} \varepsilon_{s} \sigma T_{\text {air }}$

with,

$F=(1-\alpha) S^{\downarrow}+L^{\downarrow}$

where $\alpha$ is the albedo [-], $\varepsilon_{s}$ is the surface emissivity [-], $\mathrm{S}^{\downarrow}$ and $\mathrm{L}^{\downarrow}$ are the shortwave and longwave incoming radiation $\left[\mathrm{W} \mathrm{m}^{-2}\right]$, respectively. Based on measurements of the $\mathrm{S}^{\downarrow}$ and shortwave outgoing radiation ( $\mathrm{S}^{\uparrow}$ ), the $\alpha$ is estimated to be 0.17 for the selected time period.

\subsection{Surface energy balance}

The surface energy budget characterized within Noah can be formulated as follows,

$F-\varepsilon_{s} \sigma T_{\text {skin }}^{4}=H+\lambda E+G_{0}$

The $G_{0}$ is calculated using Eq. (1) and the temperature gradient between surface and mid-point of the first soil-layer, 
whereby the $\kappa_{h}$ is calculated (e.g. Johansen, 1975; PeterLidard et al., 1998) as a weighted combination of the saturated $\left(\kappa_{\text {sat }}\right)$ and dry thermal conductivity $\left(\kappa_{\text {dry }}\right)$ depending on the degree of saturation according to,

$\kappa_{h}=K_{e}\left(\kappa_{\mathrm{sat}}-\kappa_{\mathrm{dry}}\right)+\kappa_{\mathrm{dry}}$

where $K_{e}$ is the Kersten (1949) number representing the degree of saturation determined by,

$K_{e}=\log 10\left(\frac{s m}{s m_{\mathrm{sat}}}\right)+1.0$

with $s m_{\text {sat }}$ as the saturated soil moisture content $\left[\mathrm{m}^{3} \mathrm{~m}^{-3}\right]$. $\kappa_{\text {dry }}$ is calculated using a semi-empirical equation,

$\kappa_{\text {dry }}=\frac{0.135 \gamma_{d}+64.7}{2700-0.947 \gamma_{d}}$

where $\gamma_{d}$ is the density of dry soil approximated by $\gamma_{d}=$ $\left(1-s m_{\text {sat }}\right) 2700\left[\mathrm{~kg} \mathrm{~m}^{-3}\right]$ and $\kappa_{\text {sat }}$ depends on the volume fractions of the solid particles, frozen and unfrozen soil water in the matrix,

$\kappa_{\text {sat }}=\kappa_{\text {soil }}^{\left(1-s m_{\text {sat }}\right)} \kappa_{\text {ice }}^{\left(1-s m_{\text {ice }}\right)} \kappa_{\text {h2o }}^{\left(s m_{\text {liq }}\right)}$

where $\kappa_{\text {ice }}$ and $\kappa_{\mathrm{h} 2 \mathrm{o}}$ are the thermal conductivities for ice and liquid water [ $=2.2$ and $0.57 \mathrm{~W} \mathrm{~m}^{-1} \mathrm{~K}^{-1}$, respectively], $s m_{\text {ice }}$ and $s m_{\text {liq }}$ are the frozen and liquid soil water contents $\left[\mathrm{m}^{3} \mathrm{~m}^{-3}\right]$ and $\kappa_{\text {soil }}$ is the thermal conductivity of the dry soil matrix calculated as a function of the volumetric quartz fraction $(q t z)$,

$\kappa_{\text {soil }}=\kappa_{\mathrm{qtz}}^{(\mathrm{qtz})} \kappa_{o}^{(1-\mathrm{qtz})}$

where $\kappa_{\mathrm{qtz}}$ and $\kappa_{o}$ are the thermal conductivity of quartz and others soil particles, which are set to 7.7 and 2.0 $\left[\mathrm{W} \mathrm{m}^{-1} \mathrm{~K}^{-1}\right]$, respectively.

The sensible heat flux is calculated through application of the bulk transfer relationships (e.g. Garratt, 1993), which can be written as,

$H=\rho c_{p} C_{h} u\left[T_{\text {skin }}-\theta_{\text {air }}\right]$

where $\rho$ is the air density $\left[\mathrm{kg} \mathrm{m}^{-3}\right], C_{h}$ is the surface exchange coefficient for heat [-], $u$ is the wind speed $\left[\mathrm{m} \mathrm{s}^{-1}\right.$ ] and $\theta_{\text {air }}$ is the potential air temperature [K]. The surface exchange coefficient for heat is obtained through application of the Monin-Obukhov similarity theory, whereby the ratio of the roughness length for momentum and heat transport $\left(k B^{-1}=\ln \left[z_{0 m} / z 0 h\right]\right)$ is determined by the Reynolds number dependent formulation of Zilintinkevich (1995).

Simulation of the $\lambda E$ is performed using a Penman-based diurnally dependent potential evaporation approach (Marht and Ek, 1984), and applying a Jarvis (1976)-type surface resistance parameterization similar to the one of Jacquemin and Noilhan (1990) to impose soil and atmosphere constraints to obtain the actual $\lambda E$. Assuming the surface exchange coefficient for heat $\left(C_{h}\right)$ and moisture $\left(C_{q}\right)$ are equivalent, the diurnally dependent potential evaporation can be formulated as follows,

$\lambda E_{p}=\frac{\Delta\left(R_{n}-G_{0}\right)+\rho \lambda C_{q} u\left(q_{s a t}-q\right)}{1+\Delta}$

where $\Delta$ is the slope of the saturated vapour pressure curve $\left[\mathrm{kPa} \mathrm{K}^{-1}\right], q_{\mathrm{sat}}$ and $q$ are the saturated and actual specific humidity $\left[\mathrm{kg} \mathrm{kg}^{-1}\right]$.

The actual $\lambda E$ is calculated as the sum of three components: (1) soil evaporation $\left(E_{\mathrm{dir}}\right),(2)$ evaporation of intercepted precipitation by the canopy $\left(E_{c}\right)$ and (3) transpiration through the stomata of the vegetation $\left(E_{t}\right)$. The linear method by Mahfouf and Noilhan (1991) is used to compute the soil evaporation extracted from the top soil layer, according to,

$E_{\mathrm{dir}}=\left(1-f_{c}\right)\left(\frac{s m_{1}-s m_{\mathrm{dry}}}{s m_{\mathrm{sat}}-s m_{\mathrm{dry}}}\right)^{f x} E_{p}$

where $f_{c}$ is the fractional vegetation cover, $f x$ is an empirical constant taken equal to 2.0 and subscripts " 1 ", "sat" and "dry" indicate the soil moisture content in the first soil layer, saturated soil moisture content and wilting point $\left[\mathrm{m}^{3} \mathrm{~m}^{-3}\right]$, respectively. For our Tibetan Plateau site, the $f_{c}$ is assumed to be 0.3 .

The canopy evaporation is calculated using,

$E_{c}=f_{c} E_{p}\left(\frac{c m c}{c m c_{\max }}\right)^{0.5}$

where $c m c$ and $c m c_{\max }$ are the actual and maximum canopy moisture contents $\left[\mathrm{kg} \mathrm{m}^{-2}\right]$. The canopy transpiration is determined by,

$E_{t}=f_{c} P_{c} E_{p}\left(1-\left(\frac{c m c}{c m c_{\max }}\right)^{0.5}\right)$

where $P_{c}$ is the plant coefficients defined as,

$P_{c}=\frac{1+\frac{\Delta}{R_{r}}}{1+R_{c} C_{h}+\frac{\Delta}{R_{r}}}$

with $R_{r}$ is a function of the wind speed, air temperature, surface pressure and $C_{h}$, and

$R_{c}=\frac{R_{c, \text { min }}}{\mathrm{LAIR}_{c, \text { rad }} R_{c, \text { temp }} R_{c, \text { hum }} R_{c, \text { soil }}}$

where LAI is the leaf area index $\left[\mathrm{m}^{2} \mathrm{~m}^{2}\right], R_{c, \text { min }}$ is the minimum stomatal resistance, and $R_{c \text {,rad }}, R_{c \text {,temp }}, R_{c \text {,hum }}, R_{c \text {,soil }}$ represent sub-optimal conditions for transpiration in term of incoming solar radiation, temperature, humidity and soil moisture, respectively, which are defined as,

$$
\begin{aligned}
& R_{c, \text { rad }}=\frac{R_{c, \min } / R_{c, \text { max }}+f f}{1+f f} \text { where } f f=1.10 \frac{S^{\downarrow}}{\mathrm{LAI} \cdot R_{g l}} \\
& R_{c, \text { temp }}=1-0.0016\left(T_{\mathrm{opt}}-T_{\mathrm{air}}\right)^{2}
\end{aligned}
$$


Table 2. Soil parameter sets defined for the 9 soil texture classes used within large-scale Noah applications (after Cosby et al., 1984).

\begin{tabular}{llllll}
\hline Soil texture class & $\begin{array}{l}s m_{\text {sat }} \\
{\left[\mathrm{m}^{3} \mathrm{~m}^{-3}\right]}\end{array}$ & $\begin{array}{l}\psi_{\text {sat }} \\
{\left[\mathrm{m}^{-1}\right]}\end{array}$ & $\begin{array}{l}K_{\text {sat }} \\
{\left[\mathrm{m} \mathrm{d}^{-1}\right]}\end{array}$ & $\begin{array}{l}b \text {-parameter } \\
{[-]}\end{array}$ & $\begin{array}{l}\text { Quartz } \\
{[-]}\end{array}$ \\
\hline Loamy sand & 0.421 & 0.04 & 1.22 & 4.26 & 0.82 \\
Silty clay loam & 0.464 & 0.62 & 0.17 & 8.72 & 0.10 \\
Light clay & 0.468 & 0.47 & 0.09 & 11.55 & 0.25 \\
Sandy loam & 0.434 & 0.14 & 0.45 & 4.74 & 0.60 \\
Sandy clay & 0.406 & 0.10 & 0.62 & 10.73 & 0.52 \\
Clay loam & 0.465 & 0.26 & 0.22 & 8.17 & 0.35 \\
Sandy clay loam & 0.404 & 0.14 & 0.39 & 6.77 & 0.60 \\
Organic & 0.439 & 0.36 & 0.29 & 5.25 & 0.40 \\
Glacial/land ice & 0.421 & 0.04 & 1.22 & 4.26 & 0.82 \\
\hline
\end{tabular}

$\mathrm{sm}_{\text {sat }} \sim$ saturated hydraulic conductivity;

$\psi_{\text {sat }} \sim$ soil water potential at the air entry level;

$\mathrm{K}_{\text {sat }} \sim$ saturated hydraulic conductivity;

$b$-parameter $\sim$ empirical parameter defining the shape of the retention curve;

Quartz quartz content;

$R_{c, \text { hum }}=\frac{1}{1+h_{s}\left(q_{\mathrm{sat}}-q\right)}$

$R_{c, \text { soil }}=\sum_{i=1}^{\text {nroot }} \frac{s m(i)-s m_{w l t}}{s m_{\mathrm{ref}}-s m_{\mathrm{wlt}}} f_{\mathrm{root}}(i)$

In this formulation, $s m_{\text {ref }}$ is the soil moisture content $\left[\mathrm{m}^{3} \mathrm{~m}^{-3}\right]$ below which the simulated root water uptake and transpiration are reduced and is taken equivalent to the field capacity, nroot is the number of root zone layers, $f_{\text {root }}(i)$ is the fraction of the total root zone the ith layer represents, $R_{c, \max }$ is the maximum stomatal resistance, and $R_{g l}, T_{\mathrm{opt}}$ and $H_{s}$ are semi-empirical parameter describing the optimal transpiration conditions with respect to the incoming solar radiation, air temperature and humidity.

\subsection{Application of the Noah LSM}

Description of the Noah LSM physics in the text above indicates that simulation requires the definition of a number of parameters. This comprehensive set of parameters can be subdivided into parameters describing the initial conditions, numerical discretization of the soil column, vegetation properties, soil hydraulic and thermodynamic properties. Application of Noah in a default mode accommodates four soil layers with thicknesses of $0.1,0.3,0.6$ and $1.0 \mathrm{~m}$, respectively. For each layer, initial soil moisture and temperature states should be defined.

At a global scale, 9 different texture dependent soil parameter sets (hydraulic and thermodynamic) and 13 vegetation parameter sets are defined. The soil and vegetation parameter sets used within Noah are given in Tables 2 and 3. Next to the soil texture and land cover dependent parameters, several soil and vegetation parameters are assumed to be general
Table 3. Vegetation parameter sets defined for the 13 land cover types used within large-scale Noah applications.

\begin{tabular}{|c|c|c|c|c|c|}
\hline Land cover type & $\begin{array}{l}\text { nroot } \\
{[\#]}\end{array}$ & $\begin{array}{l}R_{c, \min } \\
{\left[\mathrm{s} \mathrm{m}^{-1}\right]}\end{array}$ & $\begin{array}{l}R_{g l} \\
{\left[\mathrm{~W} \mathrm{~m}^{-2}\right]}\end{array}$ & $\begin{array}{l}H_{S} \\
{\left[\mathrm{~kg} \mathrm{~kg}^{-1}\right]}\end{array}$ & $\begin{array}{l}z_{0} \\
{[\mathrm{~m}]}\end{array}$ \\
\hline Tropical Forest & 4 & 150 & 30 & 41.69 & 2.653 \\
\hline Deciduous Trees & 4 & 100 & 30 & 54.53 & 0.826 \\
\hline Mixed Forest & 4 & 125 & 30 & 51.91 & 0.563 \\
\hline $\begin{array}{l}\text { Needleleaf } \\
\text {-evergreen forest }\end{array}$ & 4 & 150 & 30 & 47.35 & 1.089 \\
\hline $\begin{array}{l}\text { Needleleaf- } \\
\text { deciduous } \\
\text { forest (Larch) }\end{array}$ & 4 & 100 & 30 & 47.35 & 0.854 \\
\hline Savanna & 4 & 70 & 65 & 54.53 & 0.856 \\
\hline $\begin{array}{l}\text { Only Ground } \\
\text { cover (Perennial) }\end{array}$ & 3 & 40 & 100 & 36.35 & 0.035 \\
\hline Shrubs w. perennial & 3 & 300 & 100 & 42 & 0.238 \\
\hline Shrubs w. bare soil & 3 & 400 & 100 & 42 & 0.065 \\
\hline Tundra & 2 & 150 & 100 & 42 & 0.076 \\
\hline Bare soil & 3 & 400 & 100 & 42 & 0.011 \\
\hline Cultivations & 3 & 40 & 100 & 36.36 & 0.035 \\
\hline Glacial & 2 & 150 & 100 & 42 & 0.011 \\
\hline
\end{tabular}

applicable, which are given in Table 4. Somewhat peculiar is that the Leaf Area Index (LAI) is held constant at a value of $5.0 \mathrm{~m}^{2} \mathrm{~m}^{-2}$ (see also Hogue et al., 2005) instead of using other data sources, such as the ones available from satellite platforms. In this investigation, we evaluate the Noah as it is applied at a global scale and, therefore, the default LAI value is used. The impact of this large LAI values on the results is addressed in the discussion via Noah simulations performed with a more realistic LAI, which is found to be $1.2 \mathrm{~m}^{2} \mathrm{~m}^{-2}$ for the study site based on the Moderate Resolution Imaging Spectroradiometer (MODIS) LAI product. Further, it should be noted that by default one set of hydraulic and thermodynamic parameters is adopted for the entire soil column, and no distinction is made between the top- and subsoil.

\section{Evaluation of the Noah simulations obtained using de- fault parameterizations}

In this section, Noah simulations obtained by using default parameterizations are compared to soil temperature and surface energy balance measurements. For these simulations, the model is forced using the atmospheric variables measured at Naqu station and the initial soil moisture and temperature 

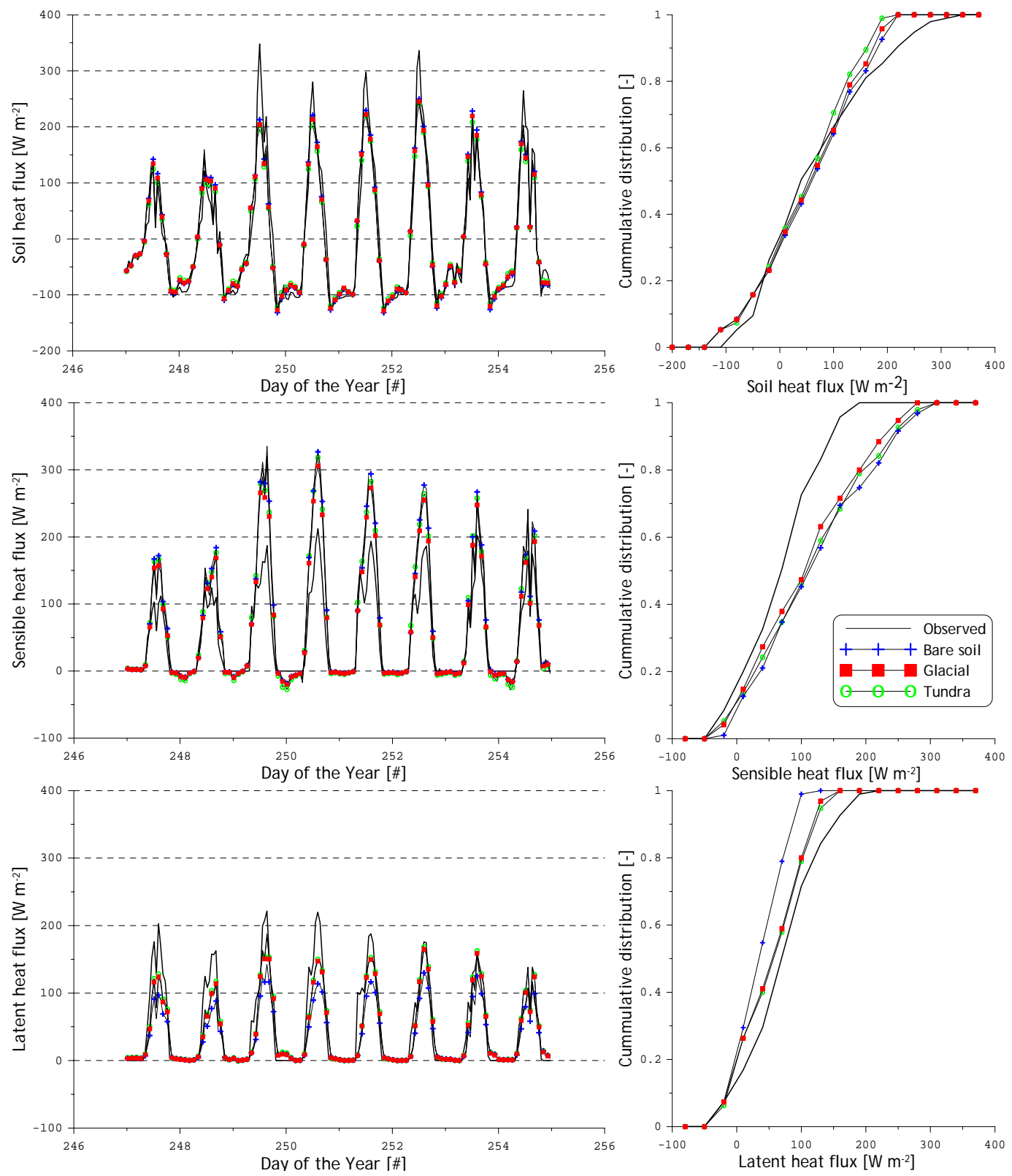

Fig. 3. Comparison of the heat fluxes measured and simulated by Noah using three default vegetation parameterizations. In the plots on the left side the measurements and simulations are presented as a time series, the right side plots show cumulative distributions.

conditions have been derived from in-situ measurements. The "Loamy sand" soil parameterization is adopted as being equivalent to the local conditions. Due to the extreme conditions on the Tibetan Plateau, assignment of a single vegetation parameterization from the 13 default land cover types is not possible. Therefore, the Noah model is run using three different vegetation parameter sets that are considered equally representative for the Tibetan Plateau, which are: tundra, bare soil and glacial.
In Fig. 3 measured and simulated heat fluxes $(H, \lambda E$ and $G_{0}$ ) obtained using the three vegetation parameter sets are plotted as a time series and cumulative distribution are shown to emphasize the differences between the measurements and simulations. Similarly, plots with the time series and the cumulative distribution of the measured and simulated soil temperatures at the surface, soil depths of $5-\mathrm{cm}$ and $25-\mathrm{cm}$ are presented in Fig. 4. In addition, the Root Mean Squared Differences (RMSD) and the bias are calculated between the measurements and simulations, and presented in Tables 5 and 6 for the surface energy balance components as well as the 
Table 4. Soil, vegetation and other parameters assumed to be constant within large-scale Noah application regardless of the soil texture, land cover class and geographic location.

\begin{tabular}{lll}
\hline Parameter & Description & Default Value \\
\hline $\mathrm{R}_{c, \max }$ & Maximum stomatal resistance & $5000\left[\mathrm{~s} \mathrm{~m}^{-1}\right]$ \\
$\mathrm{T}_{\mathrm{opt}}$ & Optimal temperature for transpiration & $24.85\left[{ }^{\circ} \mathrm{C}\right]$ \\
$\mathrm{LAI}$ & Leaf Area Index & $5.0\left[\mathrm{~m}^{2} \mathrm{~m}^{-2}\right]$ \\
$\mathrm{C}_{\text {soil }}$ & Soil heat capacity & $2.0 \cdot 10^{6}\left[\mathrm{~J} \mathrm{~m}^{-3} \mathrm{~K}^{-1}\right]$ \\
$\mathrm{C}_{\mathrm{zil}}$ & Zilintinkevich constant & $0.2[$ dimensionless $]$ \\
\hline
\end{tabular}

soil temperature states. The RMSD and bias are calculated using,

$\mathrm{RMSD}=\sqrt{\frac{1}{n} \sum\left(O_{t}-S_{t}\right)^{2}}$

bias $=\frac{1}{n} \sum O_{t}-\frac{1}{n} \sum S_{t}$

where $O_{t}$ is the measured values at time $t, S_{t}$ is the simulated value at time $t$ and $n$ is the total number of observations.

In general, the comparison indicates that the partitioning between the $H$ and $\lambda E$ is not properly simulated by Noah. Noah overestimates the measured $H$ resulting in biases of $41.25-52.69 \mathrm{~W} \mathrm{~m}^{-2}$ and underestimates the $\lambda E$ by $18.36-$ $39.53 \mathrm{~W} \mathrm{~m}^{-2}$ depending on the adopted vegetation parameterization. As a result of the biases obtained for $H$ and $\lambda E$, also the obtained RMSD's are somewhat large as compared to optimized modeling results presented in previous investigations (e.g. Sridhar et al., 2002; Yang et al., 2005; Gutmann and Small, 2007).

It should be noted that the magnitude of the $H$ overestimation is $13.34-30.55 \mathrm{~W} \mathrm{~m}^{-2}$ larger than the underestimation of the $\lambda E$. From an energy balance perspective, this difference should be compensated by other energy components, but only a small systematic difference is observed for the $G_{0}$. The explanation for this discrepancy is found through the analysis of the measured and simulated temperatures of the soil profile. Although the measured dynamic temperature range is not entirely captured by the simulations, the modeled surface temperature and 5-cm soil temperature compare reasonably well with the measurements and results RMSD's of $1.45-1.84$ and $1.08-1.80^{\circ} \mathrm{C}$, respectively. On the other hand, the $25-\mathrm{cm}$ soil temperature simulations strongly underestimate the measured diurnal temperature variation, which indicates that the heat required for the simulation of temperature variations deeper in the soil profile is not transferred into soil column. Since a relatively small amount of energy is used for heating the deeper soil profile, more energy is available for heating the atmosphere. Hence, the Noah overestimates the $H$.

Comparable results on the bias in partitioning the $H$ and $\lambda E$ have previously been reported by Kahan et al. (2006). They have reported on over- and underestimations of $H$ and
Table 5. Root mean square difference (RMSD) calculated between the measured soil temperature states and surface fluxes, and the Noah simulations.

\begin{tabular}{lllllll}
\hline Land cover & $\begin{array}{l}H \\
{\left[\mathrm{~W} \mathrm{~m}^{-2}\right]}\end{array}$ & $\begin{array}{l}\lambda E \\
{\left[\mathrm{~W} \mathrm{~m}^{-2}\right]}\end{array}$ & $\begin{array}{l}G_{0} \\
{\left[\mathrm{~W} \mathrm{~m}^{-2}\right]}\end{array}$ & $\begin{array}{l}T_{\text {skin }} \\
{\left[{ }^{\circ} \mathrm{C}\right]}\end{array}$ & $\begin{array}{l}T_{5 \mathrm{~cm}} \\
{\left[{ }^{\circ} \mathrm{C}\right]}\end{array}$ & $\begin{array}{l}T_{25 \mathrm{~cm}} \\
{\left[{ }^{\circ} \mathrm{C}\right]}\end{array}$ \\
\hline Tundra & 53.50 & 32.40 & 34.12 & 1.48 & 1.08 & 1.19 \\
Bare soil & 57.85 & 42.54 & 33.34 & 1.84 & 1.80 & 1.77 \\
Glacial & 47.41 & 33.20 & 34.23 & 1.45 & 1.28 & 1.33 \\
\hline
\end{tabular}

Table 6. Biases calculated between the measured soil temperatures and surface fluxes, and the Noah simulations.

\begin{tabular}{|c|c|c|c|c|c|c|}
\hline Land cover & $\begin{array}{l}H \\
{\left[\mathrm{~W} \mathrm{~m}^{-2}\right]}\end{array}$ & $\begin{array}{l}\lambda E \\
{\left[\mathrm{~W} \mathrm{~m}^{-2}\right]}\end{array}$ & $\begin{array}{l}G_{0} \\
{\left[\mathrm{~W} \mathrm{~m}^{-2}\right]}\end{array}$ & $\begin{array}{l}T_{\text {skin }} \\
{\left[{ }^{\circ} \mathrm{C}\right]}\end{array}$ & $\begin{array}{l}T_{5 \mathrm{~cm}} \\
{\left[{ }^{\circ} \mathrm{C}\right]}\end{array}$ & $\begin{array}{l}T_{25 \mathrm{~cm}} \\
{\left[{ }^{\circ} \mathrm{C}\right]}\end{array}$ \\
\hline Tundra & -48.91 & 18.36 & 3.80 & 1.13 & 0.59 & 0.69 \\
\hline Bare soil & -52.69 & 39.35 & 2.08 & 0.17 & -0.24 & 0.28 \\
\hline Glacial & -41.25 & 20.91 & 2.81 & 0.56 & 0.10 & 0.45 \\
\hline
\end{tabular}

$\lambda E$ measured using $\mathrm{SSiB}$ at a Sahelian study site in Niger by as much as 31.2 and $41.8 \mathrm{~W} \mathrm{~m}^{-2}$, respectively. By reducing the model's stomatal resistance (among other parameters) by more than one order of magnitude, the $\lambda E$ is increased and, because of the energy conservation principle, a reduction in $H$ is enforced. The differences between the modeling results obtained with the three vegetation parameterizations should be viewed in this context. The smallest $H$ overestimation is observed for the glacial vegetation parameterization. This parameterization includes a low value for minimum stomatal resistance $\left(R_{c, \min }\right)$ and the lowest values for the roughness length for momentum transport $\left(z_{0}\right)$, which reduces the mechanically generated atmospheric turbulent fluxes. Therefore, Noah modeling results obtained through application of the "glacial" vegetation parameterization are considered to represent the Tibetan measurements best.

Also, the inconsistency of LSM's in the simulation of the soil heat transfer has been previously recognized. Yang et al. (2005) extensively discussed the impact of the vertical heterogeneity in the soil profile for the simulation of the $H$ and $\lambda E$, and concluded that accounting for the vertical soil heterogeneity is indispensable for a proper characterization of the soil heat transfer. In the default parameterization, vertical heterogeneous soils are not accommodated in Noah, which could be the explanation for the inconsistencies between the simulated and measured temperature at a soil depth $25 \mathrm{~cm}$. This is supported by the investigation of Yang et al. (2005) who concluded that over the Tibetan prairie grasslands the roots significantly alter the STP of the top soil. 

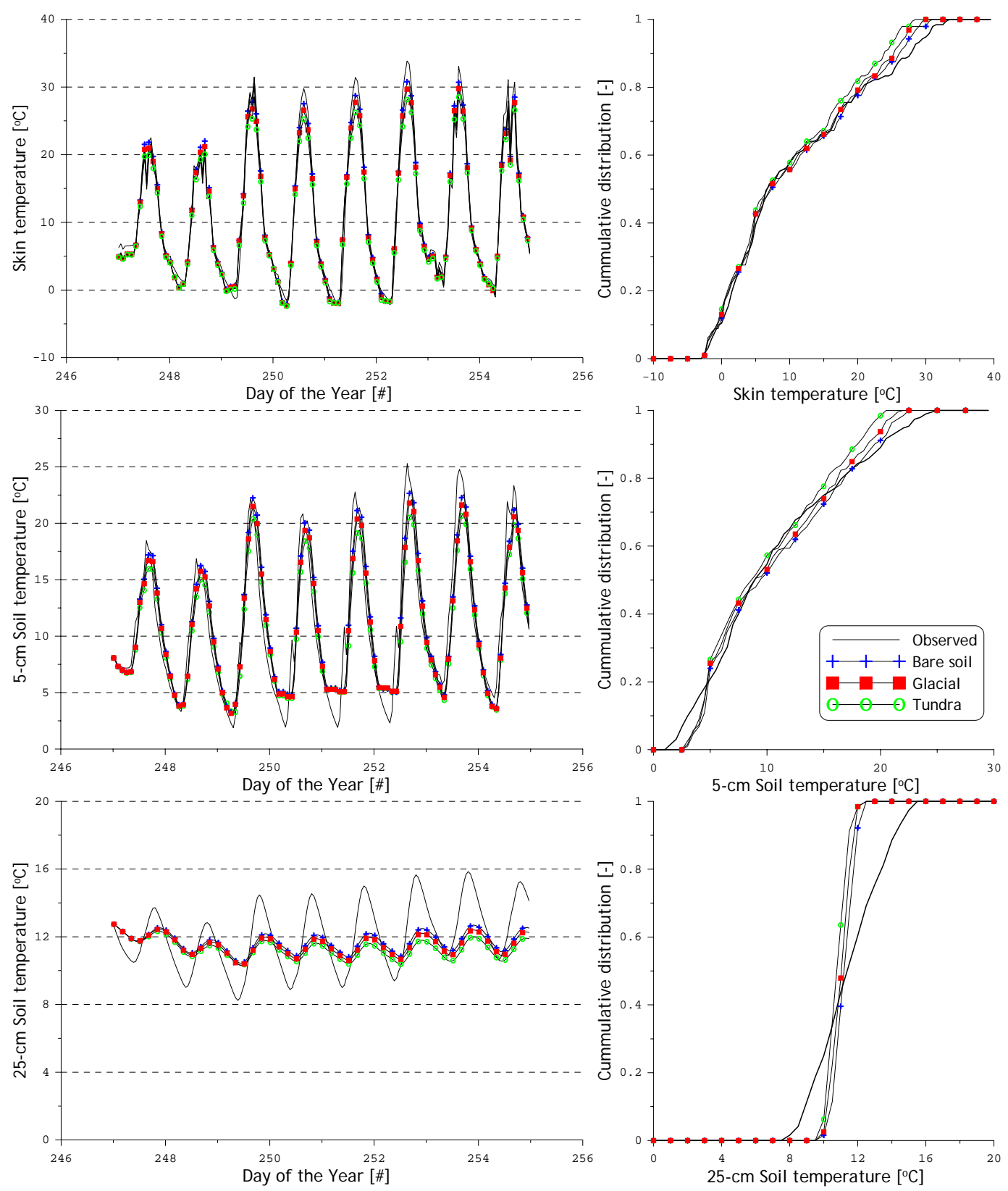

Fig. 4. Same as Fig. 3, except that the measured and simulated soil temperatures are shown for the surface and soil depths of 5-cm and $25-\mathrm{cm}$.

\section{Optimizing Noah's performance through adjustment of thermodynamic soil and vegetation parameteriza- tions}

The analysis of the Noah modeling results obtained using default soil and vegetation parameterizations against in-situ measurements has shown that the transfer of heat through the soil column and the partitioning between $H$ and $\lambda E$ are not properly simulated. In this section, the optimization of the simulation of these two land surface processes is investigated by adjusting soil and vegetation parameterizations.
These adjustments include the evaluation of different numerical discretizations of the soil layers and calibration of soil and vegetation parameters.

Calibration of the soil and vegetation parameters is performed using the Parameter Estimation (PEST, Doherty 2003) tool, which is based on the optimization of a cost function $(\Phi)$ using the Gauss-Levenberg Marquardt algorithm formulated by.

$\Phi=\sum\left(O_{t}-S_{t}\right)^{2}$ 
Table 7. Optimized values for $q t z$ parameter using the PEST tool and the Noah LSM with seven numerical discretizations for the soil profile.

\begin{tabular}{llllllll}
\hline \multicolumn{7}{c}{4 layers } & 5 layers \\
\hline Top soil thickness & $10.0 \mathrm{~cm}$ & $0.1 \mathrm{~cm}$ & $0.5 \mathrm{~cm}$ & $1.0 \mathrm{~cm}$ & $2.0 \mathrm{~cm}$ & $3.0 \mathrm{~cm}$ & $4.0 \mathrm{~cm}$ \\
quartz content & 0.82 & 1.50 & 1.58 & 1.63 & 1.66 & 1.67 & 1.68 \\
\hline
\end{tabular}

PEST allows users to assign weights to specific observations and different numerical schemes for the optimization of $\Phi$. However, the objective of this investigation is to analyze the simulation of land surface processes over a Tibetan site by Noah and not to study different calibration strategies. For a complete mathematical description of PEST, the reader is referred to Gallagher and Doherty (2007) and Doherty (2003). The default configuration of the PEST tool is used for this investigation. To assure convergence, the optimization process has been performed for a wide range of initial parameter values and during each optimization run only a single parameter is calibrated. A $\Phi$ based on the measured and simulated $G_{0}$ $\left(\Phi_{G 0}\right)$ is adopted for calibration of the STP and a $\Phi$ based on the measured and simulated $\lambda E\left(\Phi_{\lambda E}\right)$ is utilized to calibrate the vegetation parameters, independently. In this section, first, the influence of the soil parameterizations on the simulation of temperature states and surface energy balance is discussed and, then, the impact of the vegetation parameters is addressed.

\subsection{Soil heat transfer}

Since the large number of roots and the higher organic matter content in the top soil changes thermal characteristics as compared to the subsoil, the Noah is adapted to accommodate different soil thermal layers (STL's). In terms of STL's, a 10-cm topsoil layer and 190-cm subsoil layer has been selected for this investigation. For the subsoil the default parameterization for the thermal conductivity $\left(\kappa_{h}\right)$ and heat capacitiy $(C)$ have been assigned, while for the top soil a $C_{\text {soil }}$ values of $1.0 \cdot 10^{6} \mathrm{~J} \mathrm{~m}^{-3} \mathrm{~K}^{-1}$ is taken and the qtz parameter in the $\kappa_{h}$ parameterization is optimized by minimizing the $\Phi_{G 0}$. Within this calibration procedure, the upper and lower limits of the quartz content are set to 0.01 and 2.0 beyond values that are physically possible in order to maintain maximum flexibility in the modeling system. In addition, different numerical discretizations of the soil profile are evaluated, of which the default 4-soil layer and six alternate 5-soil layer models are included. Within the 5-layer model setups, thicknesses for the top soil layers of $0.1,0.5,1.0,2.0,3.0$ and $4.0 \mathrm{~cm}$ have been selected, while maintaining the total thickness of the top two soil layers $10 \mathrm{~cm}$.

The qtz parameter is calibrated for all seven soil profile discretizations and the optimized values are presented in Table 7. The "glacial" vegetation parameterization has been used for these simulations. The modeled and measured surface fluxes are presented in Fig. 5 as time series as well as cumulative distributions. Similar plots are presented in Fig. 6 for the modeled and measured soil temperature at the surface and soil depths of 5 and $25-\mathrm{cm}$. The RMSD's and biases between modeling results and measurements of the heat fluxes and soil temperatures are given in Tables 8 and 9, respectively. It should be noted that the results of the Noah simulations using the 5-layer model setup with thicknesses of the top soil of 2.0, 3.0 and $4.0 \mathrm{~cm}$ are not shown in Figs. 5 and 6.

The results presented in Figs. 5 and 6, and Tables 8 and 9 demonstrate that differentiation between the STP of the topand subsoil alone improves the simulation of the soil temperatures only slightly and even increases the differences between the simulated and measured surface fluxes. The simulation of the soil heat transfer significantly improves when an additional thin soil layer is included in the model configuration. For all six thicknesses of the top soil layer, the largest improvements are observed in the simulation of the soil temperature at a depth of $25-\mathrm{cm}\left(T_{25 \mathrm{~cm}}\right)$. The RMSD for the $T_{25 \mathrm{~cm}}\left(\mathrm{RMSD}_{\mathrm{T} 25 \mathrm{~cm}}\right)$ decreases from $1.33^{\circ} \mathrm{C}$ obtained with the "glacial" vegetation parameterization and the default numerical soil discretizations to values varying between 0.71 and $0.66^{\circ} \mathrm{C}$ depending on the thickness of the top soil layer, which is a reduction of 46.6-50.3\%. Also, the RMSD's for simulated surface temperature $\left(T_{\text {skin }}\right)$ and 5 -cm soil temperature $\left(T_{5 \mathrm{~cm}}\right)$ obtained with the 5-layer model setups decrease as compared to the model results obtained with the default 4-layer configuration. The $T_{\text {skin }}$ RMSD (RMSD $\left.{ }_{\text {Tskin }}\right)$ decreases from $1.45^{\circ} \mathrm{C}$ to values of $1.15-1.35^{\circ} \mathrm{C}$ and for the $T_{5 \mathrm{~cm}}$ RMSD (RMSD ${ }_{\mathrm{T} 5 \mathrm{~cm}}$ ) a decrease from $1.28^{\circ} \mathrm{C}$ to $1.02-1.11^{\circ} \mathrm{C}$ is observed. Both the $\mathrm{RMSD}_{\text {Tskin }}$ as well as RMSD $_{\mathrm{T} 5 \mathrm{~cm}}$ depend on the thickness of the top soil layer; the lowest $\mathrm{RMSD}_{\mathrm{Tskin}}$ and $\mathrm{RMSD}_{\mathrm{T} 5 \mathrm{~cm}}$ for a $0.1 \mathrm{~cm}$ top layer, while the lowest RMSD $_{\mathrm{T} 25 \mathrm{~cm}}$ is obtained for a $1.0 \mathrm{~cm}$ top layer.

The impact of the adjustments in soil parameterization on the simulation of the surface energy balance is primarily manifested in the $H$ and $G_{0}$. Its influence on the simulation of the $\lambda E$ is limited and resulting $\operatorname{RMSD}\left(\operatorname{RMSD}_{\lambda E}\right)$ values vary only between 33.17 and $37.04 \mathrm{~W} \mathrm{~m}^{-2}$. This is explained by the direct relationship between the soil temperature and the calculation of the $H$ and $G_{0}$, which is absent for the $\lambda E$. Computations of $H$ as well as $G_{0}$ are both based on a temperature gradient either between the surface and the air temperature (for the $H$ ) or between the surface and the mid-point of the first soil layer (for the $G_{0}$ ). For the $G_{0}$, the lowest RMSD $\left(\mathrm{RMSD}_{G 0}\right)$ is obtained using the 5-layer 

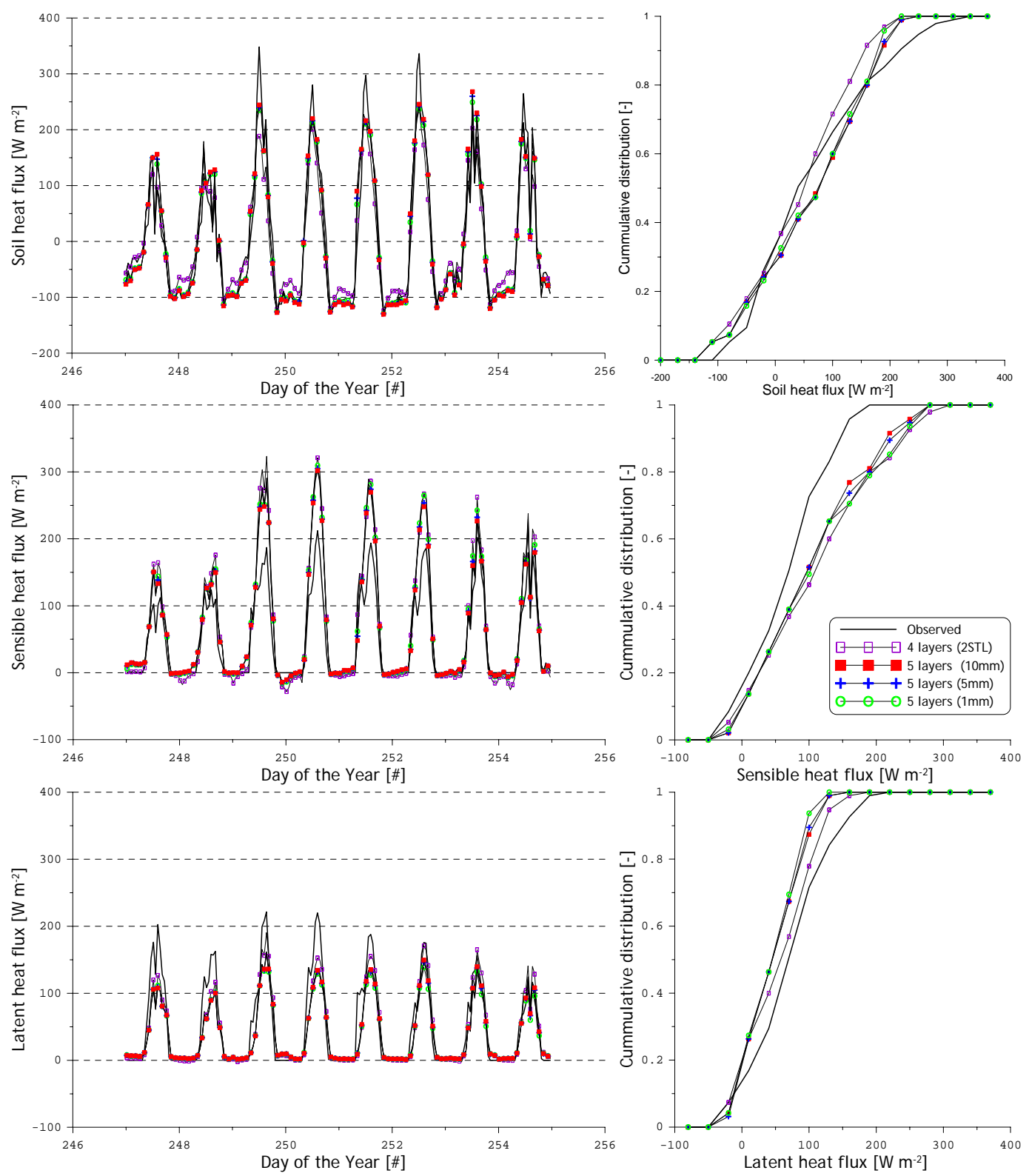

Fig. 5. Comparison of the heat fluxes measured and simulated using Noah with two soil thermal layers and different numerical discretizations of the soil profile. For reference also modeling results obtained with the default parameterizations are shown. The plots on the left side present the measurements and simulations as a time series, the right side plots show cumulative distributions.

model with a $0.1-\mathrm{mm}$ top layer $\left(33.17 \mathrm{~W} \mathrm{~m}^{-2}\right)$ because using the configuration diurnal temperature variations at the surface and at a $5-\mathrm{cm}$ soil depth are simulated best. However, the change in the simulated surface temperature modifies also the temperature gradient between the skin and air. As a result, an increase of RMSD for $H\left(\mathrm{RMSD}_{H}\right)$ is observed as the $\mathrm{RMSD}_{G 0}$ decreases, and vice versa. The lowest $\mathrm{RMSD}_{H}$ is obtained for the 5-layer model configuration using $4.0-\mathrm{cm}$ top layer, which is $35.87 \mathrm{~W} \mathrm{~m}^{-2}$. The decrease in $\mathrm{RMSD}_{H}$ observed for thicker top layer in 5-layer model configuration is coupled with a decrease in the obtained bias, which range from 40.42 to $22.9 \mathrm{~W} \mathrm{~m}^{-2}$ for top soil layer thicknesses of $0.1-4.0-\mathrm{cm}$. This indicates an improvement in the simulation of the heat flux partitioning, while even the lowest bias obtained for the $H$ as well as $\lambda E$ remain quite significant; 22.90 and $26.04 \mathrm{~W} \mathrm{~m}^{-2}$, respectively.

In general, from these modeling results it may be concluded that differentiation between top- and subsoil and including a thin top soil layer improve the soil heat transfer simulation. However, these adjustments in the soil parameterization do not improve the simulation of the surface fluxes. The $G_{0}$ simulation using $0.1-\mathrm{cm}$ top layer represent 

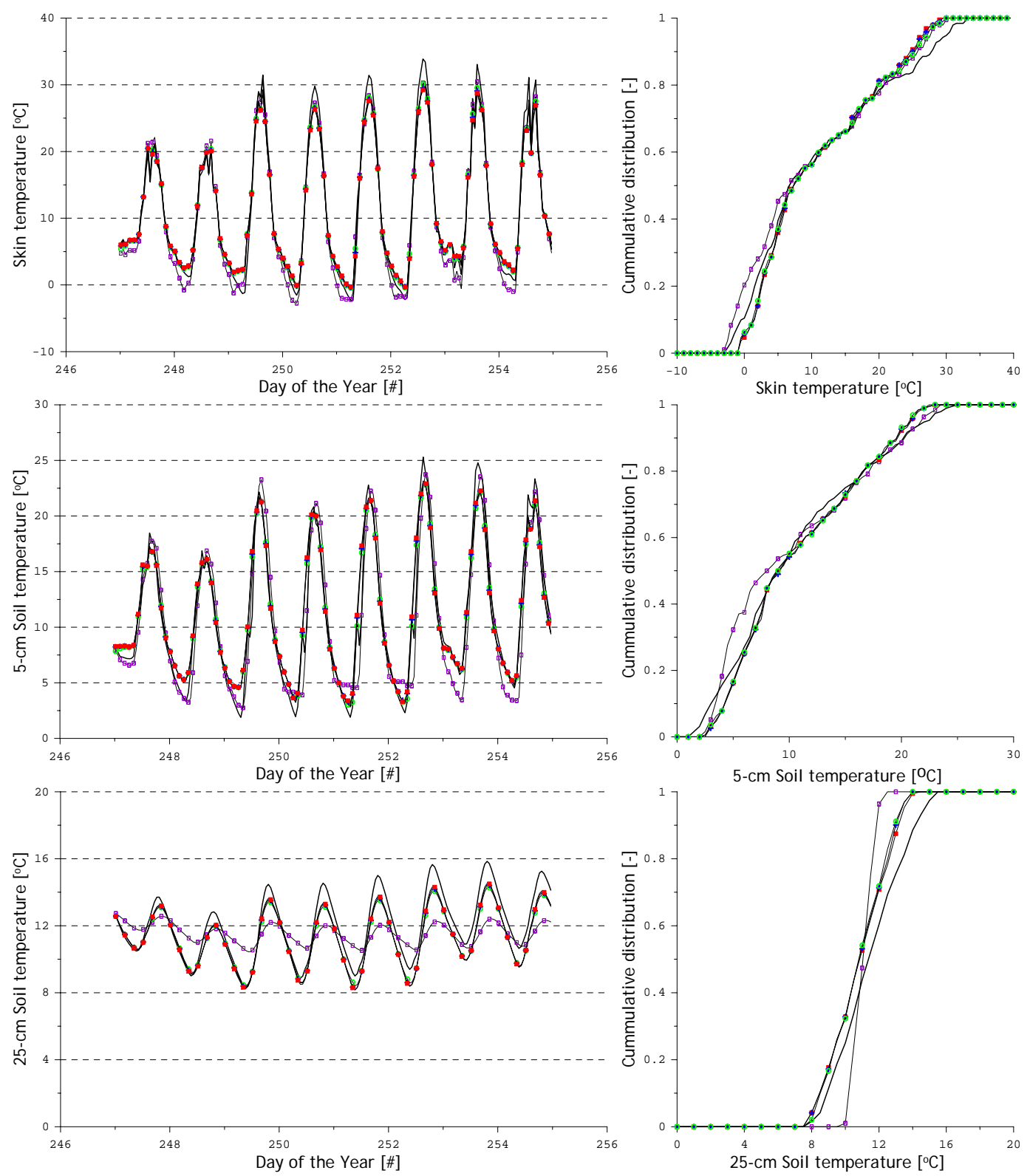

Fig. 6. Same as Fig. 5, except that the measured and simulated soil temperatures are shown for the surface and soil depth of 5-cm and 25-cm.

the measurements best, while differences between the measured and simulated $H$ are smallest using a 4.0-cm top soil layer. The overestimation of the $H$ with $0.1-\mathrm{cm}$ top soil layer might suggest that the simulated solar radiation available for heating of the air and soil is too large; meaning that the simulated solar radiation consumed by the cooling of surface through evaporation and transpiration is too low. Further, it should be noted that the optimized values for the quartz content for the all 5-layer model configurations exceed its physical limits varying between 1.50 and 1.68. An explanation for these unrealistic values will be provided in the discussion.

\subsection{Vegetation parameterization}

Amelioration of inconsistencies in simulating the partitioning between $H$ and $\lambda E$ can be obtained by adopting an aerodynamic approach through reconsideration of $k B^{-1}$ parameterization (e.g. Yang et al., 2008). However, Kahan et al. (2006) demonstrated that the simulation of the heat flux partitioning can also be improved by calibrating the vegetation parameters and showed that most notably an adjustment in stomatal resistance is needed to increase model performance. Similarly, the $R_{c, \min }$ of the Noah vegetation parameterization is used, here, to improve the simulated heat flux partitioning. In addition, the optimum temperature for 
Table 8. RMSD's calculated between the measured soil temperature states and surface fluxes, and modelling results obtained with Noah configured to accommodate different STP for the top- and subsoil and different numerical discretizations of the soil profile.

\begin{tabular}{|c|c|c|c|c|c|c|c|}
\hline \multicolumn{2}{|c|}{ Soil discretization } & \multirow{2}{*}{$\begin{array}{l}H \\
{\left[\mathrm{~W} \mathrm{~m}^{-2}\right]}\end{array}$} & \multirow{2}{*}{$\begin{array}{l}\lambda E \\
{\left[\mathrm{~W} \mathrm{~m}^{-2}\right]}\end{array}$} & \multirow{2}{*}{$\begin{array}{l}G_{0} \\
{\left[\mathrm{~W} \mathrm{~m}^{-2}\right]}\end{array}$} & \multirow{2}{*}{$\begin{array}{l}T_{\text {skin }} \\
{\left[{ }^{\circ} \mathrm{C}\right]}\end{array}$} & \multirow{2}{*}{$\begin{array}{l}T_{5 \mathrm{~cm}} \\
{\left[{ }^{\circ} \mathrm{C}\right]}\end{array}$} & \multirow{2}{*}{$\begin{array}{l}T_{25 \mathrm{~cm}} \\
{\left[{ }^{\circ} \mathrm{C}\right]}\end{array}$} \\
\hline \# layers & Top soil thickness & & & & & & \\
\hline \multirow[t]{3}{*}{4 layers } & $10.0[\mathrm{~cm}]$ & 52.72 & 33.17 & 41.28 & 1.40 & 1.49 & 1.32 \\
\hline & $0.1[\mathrm{~cm}]$ & 46.92 & 37.04 & 33.17 & 1.15 & 1.02 & 0.71 \\
\hline & $0.5[\mathrm{~cm}]$ & 44.34 & 36.21 & 34.73 & 1.25 & 1.05 & 0.68 \\
\hline \multirow{4}{*}{ 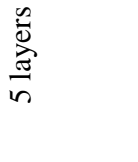 } & $1.0[\mathrm{~cm}]$ & 43.30 & 36.13 & 36.83 & 1.32 & 1.07 & 0.66 \\
\hline & $2.0[\mathrm{~cm}]$ & 43.24 & 36.06 & 39.34 & 1.36 & 1.09 & 0.66 \\
\hline & $3.0[\mathrm{~cm}]$ & 43.51 & 35.97 & 40.47 & 1.35 & 1.11 & 0.67 \\
\hline & $4.0[\mathrm{~cm}]$ & 35.87 & 35.89 & 40.68 & 1.35 & 1.03 & 0.67 \\
\hline
\end{tabular}

Table 9. Same as Table 8, except the biases are presented.

\begin{tabular}{|c|c|c|c|c|c|c|c|}
\hline \multicolumn{2}{|c|}{ Soil discretization } & $\begin{array}{l}H \\
{\left[\mathrm{~W} \mathrm{~m}^{-2}\right]}\end{array}$ & $\begin{array}{l}\lambda E \\
{\left[\mathrm{~W} \mathrm{~m}^{-2}\right]}\end{array}$ & $\begin{array}{l}G_{0} \\
{\left[\mathrm{~W} \mathrm{~m}^{-2}\right]}\end{array}$ & $\begin{array}{l}T_{\text {skin }} \\
{\left[{ }^{\circ} \mathrm{C}\right]}\end{array}$ & $\begin{array}{l}T_{5 \mathrm{~cm}} \\
{\left[{ }^{\circ} \mathrm{C}\right]}\end{array}$ & $\begin{array}{l}T_{25 \mathrm{~cm}} \\
{\left[{ }^{\circ} \mathrm{C}\right]}\end{array}$ \\
\hline 4 layers & $10.0[\mathrm{~cm}]$ & -46.40 & 18.70 & 17.33 & 0.84 & 0.30 & 0.44 \\
\hline \multirow{6}{*}{ 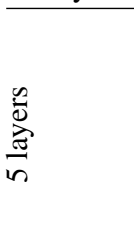 } & $0.1[\mathrm{~cm}]$ & -40.42 & 31.07 & 2.31 & 0.05 & -0.21 & 0.67 \\
\hline & $0.5[\mathrm{~cm}]$ & -37.69 & 29.12 & 3.92 & 0.06 & -0.28 & 0.65 \\
\hline & $1.0[\mathrm{~cm}]$ & -35.91 & 28.19 & 5.35 & 0.06 & -0.30 & 0.63 \\
\hline & $2.0[\mathrm{~cm}]$ & -34.86 & 27.08 & 5.64 & 0.08 & -0.29 & 0.64 \\
\hline & $3.0[\mathrm{~cm}]$ & -34.62 & 26.45 & 5.33 & 0.10 & -0.28 & 0.64 \\
\hline & $4.0[\mathrm{~cm}]$ & -22.90 & 26.04 & 5.30 & 0.11 & -0.25 & 0.65 \\
\hline
\end{tabular}

transpiration $\left(T_{\mathrm{opt}}\right)$, currently fixed at a value of $24.85^{\circ} \mathrm{C}$, may need to be tuned to represent the Tibetan conditions.

Ideally, the $R_{c, \min }$ and $T_{\mathrm{opt}}$ would be obtained from long term data sets as has been done by Gimanov et al. (2008). This reaches, however, beyond our objective to identify the adjustments in soil and vegetation parameterization needed to improve Noah's performance over the selected Tibetan site for a short 7-day period. Therefore, the parameters $R_{c \text {, min }}$ and $T_{\mathrm{opt}}$ are calibrated by minimizing the cost function between the measured and simulated $\lambda E$. For this optimization procedure, the 5-layer Noah model configuration is used with a $0.5 \mathrm{~cm}$ top soil layer and a $q t z$ value of 1.58 . The calibration of the $R_{c, \text { min }}$ and $T_{\text {opt }}$ yields values of $49.88 \mathrm{~s} \mathrm{~m}^{-1}$ and 7.21 ${ }^{\circ} \mathrm{C}$, respectively. Through the optimization, the $R_{c, \min }$ is reduced by $100.12 \mathrm{~s} \mathrm{~m}^{-1}$ and $T_{\mathrm{opt}}$ by $17.61^{\circ} \mathrm{C}$ in comparison to the default parameterization. Both changes to the two plant physiological parameters can be argued. Growing seasons on the plateau are short and, in this short period, vegetation should be productive in order to be able to survive the harsh Tibetan environment. Further, temperatures on the plateau are, generally, lower than at sea level; a lower temperature at which plants transpire optimally is, therefore, required. At the same time, the validity of the default $T_{\text {opt }}$ can be questioned for all environments that substantially differ from the humid climate for the original parameterization (Dickinson, 1984). A climate dependent parameterization could be considered for global Noah applications, but this extends beyond the scope of this investigation.
The modeling results of Noah simulations with the optimized vegetation parameters are plotted against measurements, which are presented in Figs. 7 and 8 for the heat fluxes and soil temperatures, respectively. For comparison purposes, a selection of Noah simulations discussed previously are also presented in Figs. 7 and 8, which are; (1) the default 4-layer model with the "glacial" vegetation parameters; (2) the 4-layer model with two STL's and "glacial" vegetation parameters; and (3) the 5-layer model with two STL's, $0.5-\mathrm{cm}$ top layer and "glacial" vegetation parameters. In addition, the basic statistics are presented in the plots, such the coefficient of determination $\left(R^{2}\right)$, RMSD and bias.

Comparison of the plots in Figs. 7 and 8 shows that the adjustments in the parameterization of STP improves the simulation of the soil temperature states, but does not result in a reduction in the differences between the simulated and measured surface fluxes. Through the calibration of the $R_{c, \text { min }}$ and $T_{\mathrm{opt}}$, the simulated partitioning between $H$ and $\lambda E$ represents better the energy budget measurements. The RMSD's obtained for the $H$ and $\lambda E$ are reduced from 47.4 and $33.2 \mathrm{~W} \mathrm{~m}^{-2}$ for the default simulations to 33.3 and $26.5 \mathrm{~W} \mathrm{~m}^{-2}$ for optimized simulations, respectively. Similar results have been presented in the Kahan et al. (2006). They showed for an application of the SSiB LSM to a Sahelian study area that lowering the model constraints for the transpiration, not only increases simulated $\lambda E$, but also reduces the overestimation in the $H$. 


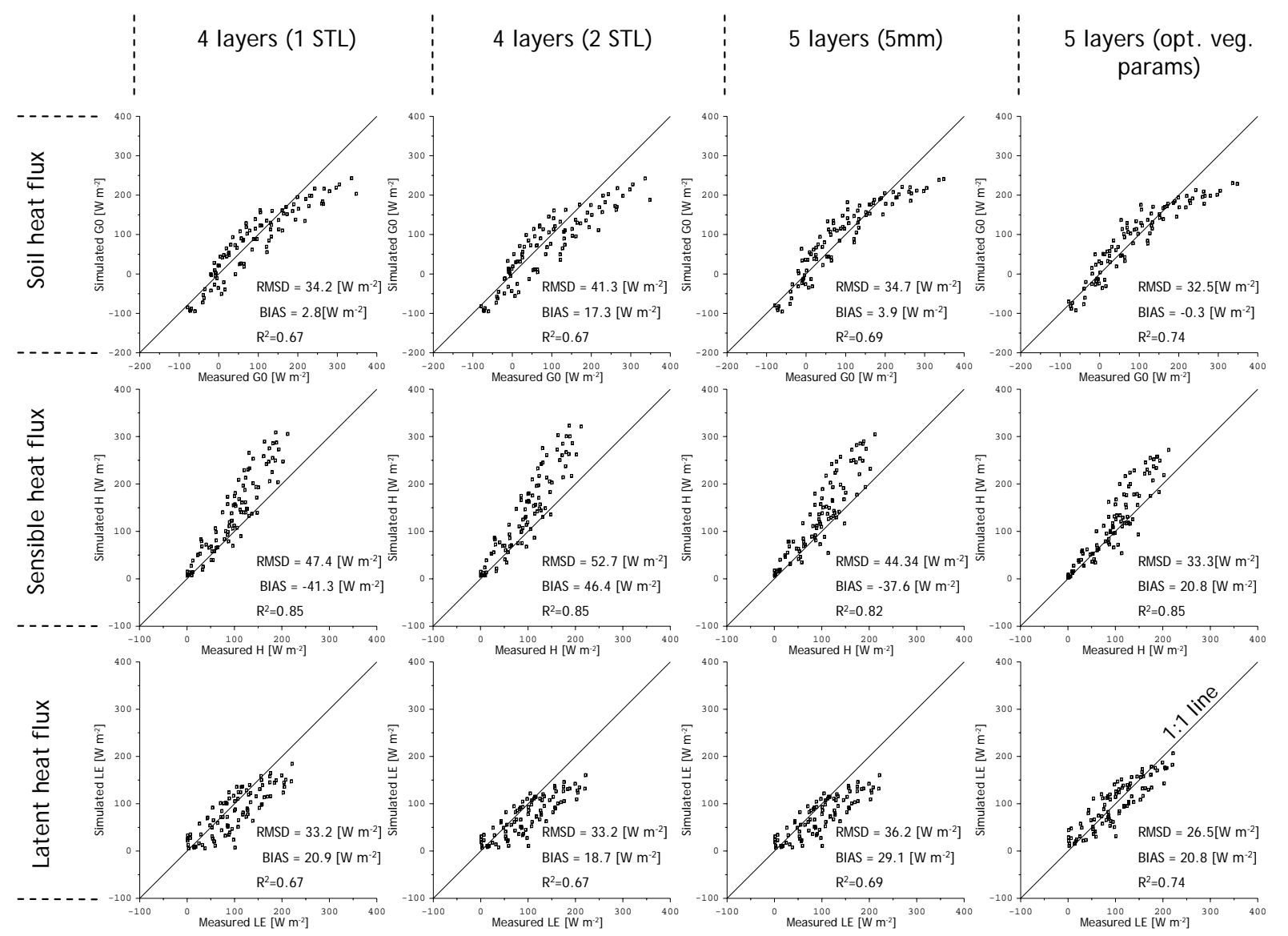

Fig. 7. Scatter plots of surface fluxes $\left(G_{0}, H, \lambda E\right)$ measured and simulated using Noah in its (1) default configuration; (2) default numerical discretizations of the soil profile and 2 STL's; (3) 5-layer model setup, 2 STL's and top layer of $0.5 \mathrm{~cm}$; (4) same as (3) except the vegetation parameters are calibrated.

\section{Discussion}

The adjustments in the parameterization of the STP and calibration of the vegetation parameters, $R_{c, \min }$ and $T_{\mathrm{opt}}$, have ameliorated the simulation of the soil heat transfer and reduced uncertainties in the simulated $H$ and $\lambda E$ to levels comparable as are reported in previous investigations (e.g., Sridhar et al., 2003; Gutmann and Small, 2007; and Pauwels et al., 2008). Despite the optimized Noah simulations are able to represent the soil temperature and surface energy balance measurements better, still some inconsistencies in the modeling results can be observed when radiative forcings become large. For example, Noah systematically overestimates the measured $H$ at values larger than approximately $150 \mathrm{~W} \mathrm{~m}^{-2}$, which coincides with underestimation of the $G_{0}$ and $T_{\text {skin }}$ when the measured values are larger than approximately $150 \mathrm{~W} \mathrm{~m}^{-2}$ and $20^{\circ} \mathrm{C}$, respectively. Apparently, under large radiative forcings Noah is not able to simulate $T_{\text {skin }}$ increase measured on the Tibetan Plateau. Therefore, the simulated temperature gradients between the surface and atmosphere, and between surface and the mid-point of the first soil layer become too large and too small, respectively. As a result, an over- and underestimation of the measured $H$ and $G_{0}$ are observed. The explanation of this discrepancy in the simulated $T_{\text {skin }}$ is twofold.

First, the surface exchange coefficient for heat $\left(C_{h}\right)$ may not be properly parameterized for the Tibetan conditions. Noah uses the Reynolds number dependent method proposed by Zilintinkevich (1995) to determine the $k B^{-1}$. However, Yang et al. (2008) showed for bare soil surfaces that Reynolds number dependent $k B^{-1}$ methods, in general, tend to underestimate the strong diurnal $k B^{-1}$ variations observed over the Tibetan Plateau (e.g. Ma et al. 2005 and Yang et al. 2003). A $k B^{-1}$ underestimation during daytime results in more efficient heat transfer between the soil surface and the atmosphere, which causes an $H$ overestimation and explains also the discrepancy between the measured and simulated $T_{\text {skin }}$. Other $k B^{-1}$ methods (e.g. Su et al. 2001 and Yang et al. 2002) that are able to capture this diurnal $k B^{-1}$ variation would further improve Noah's overall performance over the Tibetan Plateau. This reaches, however, beyond the scope of this investigation. For evaluations of the available 

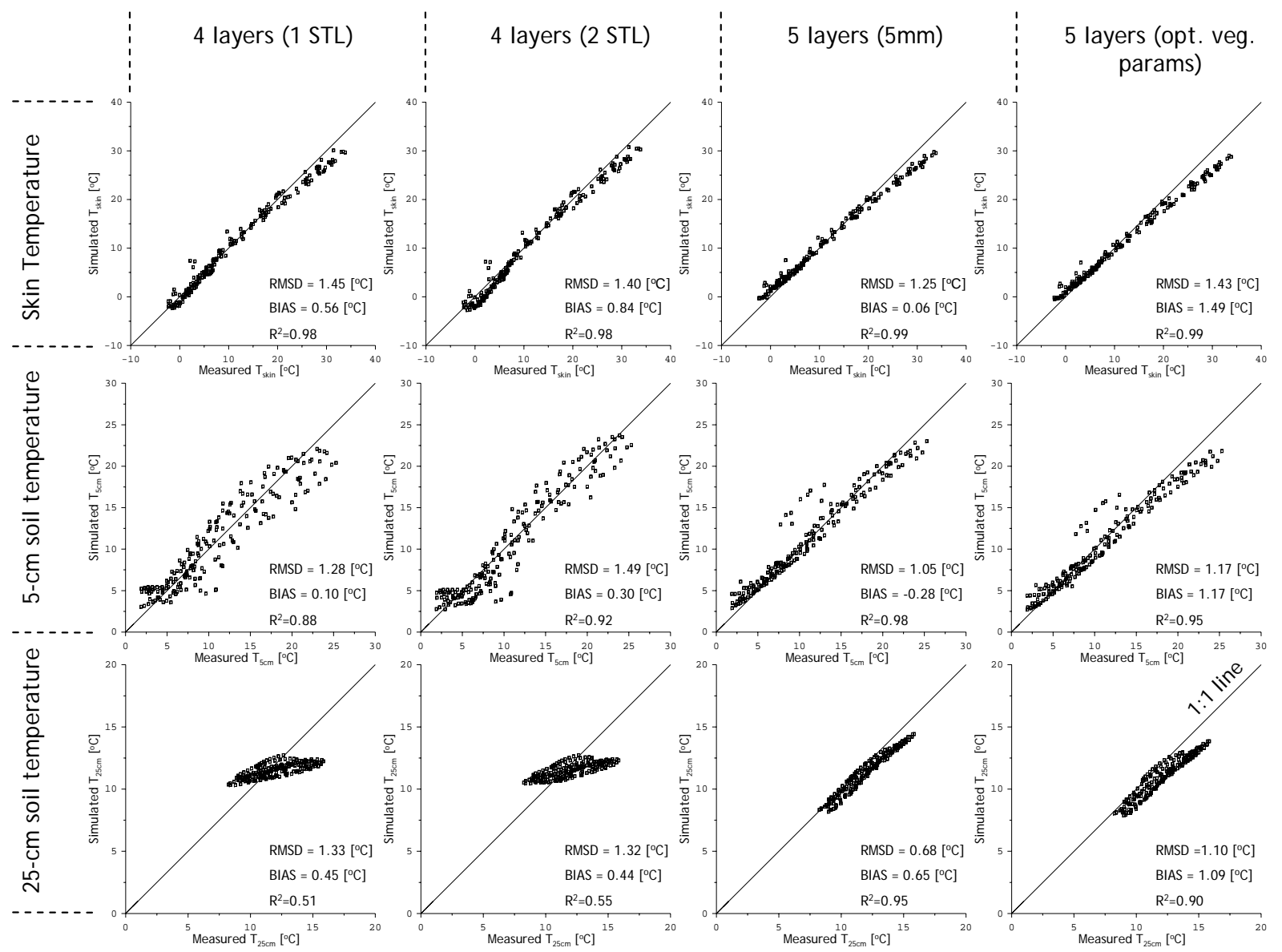

Fig. 8. Same as Fig. 7 expect that the temperature states $\left(T_{\text {skin }}, T_{5 \mathrm{~cm}}\right.$ and $\left.T_{25 \mathrm{~cm}}\right)$ are shown here.

$k B^{-1}$ methods readers are referred to Liu et al. (2007) and Yang et al. (2008).

Second, the linearization of the surface energy balance (see Eq. (10)) utilized to compute the $T_{\text {skin }}$ contributes to explaining the differences between the simulated and measured $T_{\text {skin. }}$. This approximation is exact when $T_{\text {air }}$ is equivalent to $T_{\text {skin }}$ and loses its validity as the difference between $T_{\text {air }}$ and $T_{\text {skin }}$ increases. For our Tibetan study site, differences between the $T_{\text {air }}$ and $T_{\text {skin }}$ can be expected to be significantly larger than at sea level because the air pressure is much lower and fewer air molecules are available to transport energy from the surface towards the air. To demonstrate the impact of the applied approximation for our Tibetan site, the measured $T_{\text {skin }}$ and $T_{\text {air }}$, the $T_{\text {skin }}$ calculated by using Eq. (10) and are plotted in Fig. 9. This plot shows that the applied approximation holds rather well during nighttime. After sunrise, however, differences between measured $T_{\text {air }}$ and $T_{\text {skin }}$ increase resulting in a discrepancy between the measured and approximated $T_{\text {skin }}$ of more than $10^{\circ} \mathrm{C}$ at midday. Obviously, this leads to an underestimation of $T_{\text {skin }}$ even when the parameterization of the soil-vegetation-atmosphere system is agreement with the local conditions.
Within the uncertainties embedded in the $C_{h}$ calculation and in the linearization applied for the $T_{\text {skin }}$ simulation lies also the explanation for the unrealistically high values of the calibrated qtz parameter. With the increase of the qtz parameter, the thermal heat conductance is raised to increase the transport of heat into soil and to compensate for the lower simulated temperature gradient between surface and the mid point of the first soil layer. When the qtz parameter is not used to compensate for the $T_{\text {skin }}$ underestimation, biases arise in the simulation of the soil temperature profile as occurs in Noah applications in the default configuration.

Another issue in the default Noah configuration that has not been addressed in the text above is the LAI value, which is fixed at a value of $5.0 \mathrm{~m}^{2} \mathrm{~m}^{-2}$. To evaluate the influence of this LAI value on the results presented in this study, the optimization of the qtz parameter has been performed using a LAI of $1.2 \mathrm{~m}^{2} \mathrm{~m}^{-2}$ (obtained from the MODIS LAI product) for the Noah 4- and 5-layer configurations with 2 STL's, whereby for the 5-layer configuration a top soil thickness of $0.5 \mathrm{~cm}$ was used. This optimization results in qtz values 0.66 and 1.45 for the 4- and 5-layer discretization, respectively. The optimized qtz parameters are lower and, thus, in the case 


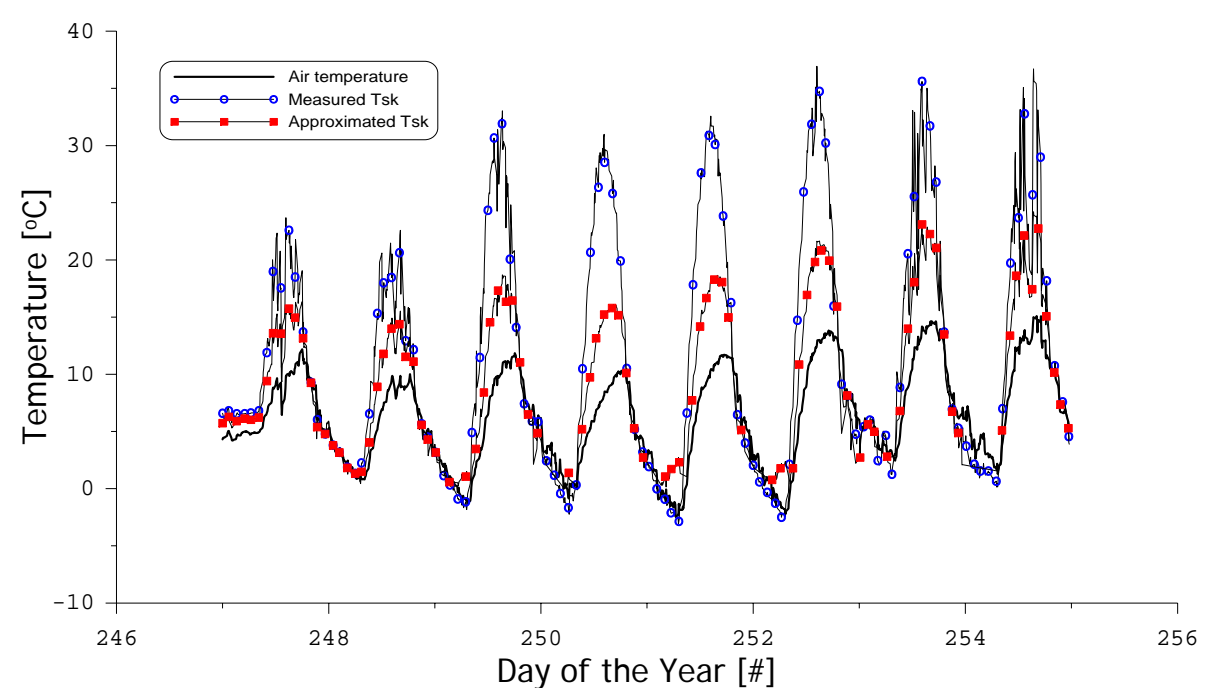

Fig. 9. Measurements of the air and surface temperature, and the surface temperature approximated using Eq. (10) plotted as a time series for the analyzed period of meteorological forcing collected at a Tibetan Plateau site.

of the 5-layer configuration closer to a value that is realistically possible, but is still far too high.

Using the qtz value of 1.45 and 5-layer discretization with a $0.5 \mathrm{~cm}$ top layer, the vegetation parameters, $R_{c, \min }$ and $T_{\mathrm{opt}}$, have also been recalibrated with a LAI of $1.2 \mathrm{~m}^{2} \mathrm{~m}^{-2}$, which results in values of $20.89 \mathrm{~s} \mathrm{~m}^{-1}$ and $9.73^{\circ} \mathrm{C}$, respectively. Compared to the vegetation parameter presented above, the $R_{c}$, min has decreased by more than a factor two, while the $T_{\text {opt }}$ has increased only slightly. This large reduction in $R_{c, \text { min }}$ follows directly from Eq. (24), in which the $R_{c, \text { min }}$ and LAI have an opposite effect on the calculation of the $R_{c}$. Thus, the decrease in LAI is for a large part compensated within the model calibration by decreasing the $R_{c}$, min.

As to determine whether using the MODIS LAI improves Noah's performance, RMSD values between the measured and simulated soil temperatures and heat fluxes have been computed for the three additional Noah simulations and are presented in Table 10. Comparison of the RMSD values of Table 10 with the results presented previously shows that the simulation of the temperatures across the soil profile improves somewhat. However, Noah's overall ability to simulate the heat fluxes decreases when using the MODIS LAI. Apparently, Noah has been tuned to perform optimally using LAI of $5.0 \mathrm{~m}^{2} \mathrm{~m}^{-2}$, which is probably the reason for using a fixed value for large-scale Noah applications.

\section{Conclusions}

In this paper, adjustments in the soil and vegetation parameterizations required to be able to reproduce the soil temperature states and surface fluxes using the Noah LSM are investigated using a 7-day period of in-situ measurements collected at a study site on the Tibetan Plateau. Analysis
Table 10. RMSD values calculated between soil temperatures and surface fluxes measured and simulated by Noah using a LAI value of $1.2 \mathrm{~m}^{2} \mathrm{~m}^{-2}$; 4-layer $\sim$ Noah simulations obtained with the default 4 layer soil discretization and calibrating the $q t z$ parameter $(=0.66)$; 5-layer $\sim$ Noah simulation obtained using 5 layers (top layer $=0.5 \mathrm{~cm})$ and calibrating the qtz parameter $(=1.45) ; 51+v e g \sim$ Noah simulations obtained 5-layer soil discretization and qtz parameter and calibrating the vegetation parameters $R_{c, \text { min }}$ and $T_{\mathrm{opt}}$ $\left(20.89 \mathrm{~s} \mathrm{~m}^{-1}\right.$ and $\left.9.73^{\circ} \mathrm{C}\right)$.

\begin{tabular}{lllllll}
\hline & $\begin{array}{l}H \\
{\left[\mathrm{~W} \mathrm{~m}^{-2}\right]}\end{array}$ & $\begin{array}{l}\lambda E \\
{\left[\mathrm{~W} \mathrm{~m}^{-2}\right]}\end{array}$ & $\begin{array}{l}G_{0} \\
{\left[\mathrm{~W} \mathrm{~m}^{-2}\right]}\end{array}$ & $\begin{array}{l}T_{\text {skin }} \\
{\left[{ }^{\circ} \mathrm{C}\right]}\end{array}$ & $\begin{array}{l}T_{5 \mathrm{~cm}} \\
{\left[{ }^{\circ} \mathrm{C}\right]}\end{array}$ & $\begin{array}{l}T_{25 \mathrm{~cm}} \\
{\left[{ }^{\circ} \mathrm{C}\right]}\end{array}$ \\
\hline 4 layer & 67.29 & 43.46 & 38.64 & 1.48 & 1.08 & 1.19 \\
5 layer & 58.74 & 50.92 & 35.81 & 0.97 & 1.04 & 0.51 \\
51+veg. & 35.41 & 26.85 & 33.78 & 1.33 & 1.18 & 1.09 \\
\hline
\end{tabular}

of the results from simulations obtained through application of the default parameterization has shown that (1) heat transfer through the soil column is not represented adequately, (2) partitioning between the sensible $(H)$ and latent heat $(\lambda E)$ flux is biased. Amelioration of the parameterization of these land surface processes is achieved through adjustment of soil and vegetation parameterizations.

Through differentiating between the soil thermal properties of a top- and subsoil, and including a thin top soil layer, uncertainties in the simulation of the soil heat transfer are reduced and RMSD's between the measured and simulated $T_{\text {skin }}, T_{5 \mathrm{~cm}}$ and $T_{25 \mathrm{~cm}}$ are obtained of $1.25^{\circ} \mathrm{C}, 1.05^{\circ} \mathrm{C}$ and $0.68^{\circ} \mathrm{C}$ by using a $0.5 \mathrm{~cm}$ thick top soil layer. It is found that adding a thin top soil layer has stronger effect than differentiating between the soil thermal properties of a top- and subsoil. A decrease in the vegetation parameters, $R_{c, \min }$ and $T_{\text {opt }}$, constraining the transpiration reduces the RMSD for the 
$\lambda E$ from $33.2 \mathrm{~W} \mathrm{~m}^{-2}$ obtained using the default Noah configuration to $26.5 \mathrm{~W} \mathrm{~m}^{-2}$ using the optimized parameterization. In addition, the improvement in the $\lambda E$ simulation also influences the $H$ simulation and decreases the RMSD from 47.41 to $33.3 \mathrm{~W} \mathrm{~m}^{-2}$, while the differences between the measured and simulated $G_{0}$ do not change significantly.

Although the adjustments in the parameterization of the STP and calibration of vegetation parameters improved Noah's capability of representing the soil temperature states and the surface energy balance components measured on the Tibetan Plateau, under conditions of the high radiative forcings an underestimation is observed of measured $T_{\text {skin }}$. This underestimation of the $T_{\text {skin }}$ results in an overestimation of the $H$ and underestimation $G_{0}$. The explanation for the discrepancy in the $T_{\text {skin }}$ simulation is twofold. First, the surface exchange coefficient for heat may not be properly parameterized. Second, the approximation, adopted for linearization of the surface energy balance for the $T_{\text {skin }}$ calculation, introduces some uncertainties when differences between the measured $T_{\text {skin }}$ and $T_{\text {air }}$ are large, which are typical midday conditions on the Tibetan Plateau.

Edited by: J. Wen

\section{References}

Chen, F., Janjic, Z., and Mitchell, K.: Impact of atmospheric surface-layer parameterizations in the new land-surface scheme of the NCEP mesoscale ETA model, Bound.-Lay. Meteorol., 85, 391-421, 1997.

Cosby, B. J., Hornberger, G. M., Clapp, R. B., and Ginn, T. R.: Water Resour. Res., 20, 682-690, 1984.

Dickinson, R. E.: Modeling evapotranspiration for threedimensional global climate models, in: Climate processes and climate sensitivity, editedy by: Hansen, J. E. and Takahashi, T., American Geophysical Union, Geophys. Monogr., 29, 58-72, 1984.

Dickinson, R. E., Oleson, K. W., Bonan, G., Hoffman, F., Thornton, P., Vertenstein, M., Yang, Z.-L., and Zeng, X.: The community land model and its climate statistics as a component of the community climate system model, J. Climate, 19, 2302-2324, 2006.

Doherty, J.: Manual for the PEST Surface Water Modelling Utilities, Watermark Numerical Computing, Australia, available at http://www.sspa.com/pest, 2003.

Duan, Q., Schaake, J., Andréassian, V., et al.: Model parameter estimation experiment (MOPEX): An overview of science strategy and major results from the second and third workshops, J. Hydrol., 320, 3-17, 2006.

Ek, M. B., Mitchell, K. E., Lin, Y., Rogers, E., Grunmann, P., Koren, V., Gayno, G., and Tarpley, J. D.: Implementation of Noah land surface model advances in the National Centers for Environmental Prediction operational mesoscale Eta model, J. Geophys. Res., 108, 8851, doi:10.1029/2002JD003296, 2003.
Gallagher, M. and Doherty, J.: Parameter estimation and uncertainty analysis for a watershed model, Environ. Modell. Softw., 22, 1000-1020, 2007.

Garratt, J. R.: Sensitivity of climate simulations to land-surface and atmospheric boundary-layer treatments - A review, J. Climate, 6, 419-448, 1993.

Gilmanov, T. G., Soussana, J. F., Aires, L., et al.: Partitioning European grassland net ecosystem $\mathrm{CO}_{2}$ exchange into gross primary productivity and ecosystem respiration using light response function analysis, Agr. Ecosyst. Environ., 121, 93-120, 2007.

Gutmann, E. D. and Small, E. E.: A comparison of land surface model soil hydraulic properties estimated by inverse modeling and pedotransfer functions, Water Resour. Res., 43, W05418, doi:10.1029/2006WR005135, 2007.

Gulden, L. E., Rosero, E., Yang, Z., Rodell, M., Jackson, C. S., Niu, G., Yeh, P. J.-F., and Famiglietti, J.: Improving landsurface model hydrology: Is an explicit aquifer model better than a deeper soil profile?, Geophys. Res. Lett., 34, L09402, doi:10.1029/2007GL029804, 2007.

Hillel, D.: Environmental soil physics, Academic Press, 771 pp., 1998.

Hogue, T. S., Bastidas, L., Gupta, H., Sorooshian, S., Mitchell, K., and Emmerich, W.: Evaluation and transferability of the Noah land surface model in semiarid environments, J. Hydrometeorol., 6, 68-83, 2005.

International GEWEX Project Office: GSWP-2: The Second Global Soil Wetness Project Science and Implementation Plan. IGPO Publication Series No. 37, 65 pp., 2002.

Jacquemin, B. and Noilhan, J.: Sensitivity study and validation of a land surface parameterization using the HAPEX-MOBILHY data set, Bound.-Lay. Meteorol., 52, 93-134, 1990.

Jarvis, P. G.: The interpretation of the variations in leaf water potential and stomatal conductance found in canopies in the field, Philos. T. Roy. Soc. B, 273, 593-610, 1976.

Johansen, O.: Thermal conductivity of soils. Ph.D thesis, University of Trondheim, 236 pp., 1975.

Kahan, D. S., Xue, Y., and Allen S. J.: The impact of vegetation and soil parameters in simulations of surface energy and water balance in the semi-arid sahel: A case study using SEBX and HAPEX-Sahel data, J. Hydrol., 320, 238-259, 2006.

Kato, H., Rodell, M., Beyrich, F., Cleugh, H., van Gorsel, E., Liu, H., and Meyers, T. P.: Sensitivity of land surface simulations to model physics, land characteristics, and forcings, at four CEOP Sites, J. Meteorol. Soc. Jpn., 87A, 187-204, 2007.

Kersten, M. S.: Thermal properties of soils. University of Minnesota Engineering Experiment Station Bulletin 28, 227 pp., available from University of Minnesota Agricultural Experiment Station, St. Paul, MN 55108, 1949.

Koster, R. D., Dirmeyer, P. A., Guo, Z., et al.: Regions of strong coupling between soil moisture and precipitation, Science, 305 , 1138-1140, 2004.

Liu, S., Lu, L., Mao, D., and Jia, L.: Evaluating parameterizations of aerodynamic resistance to heat transfer using field measurements, Hydrol. Earth Syst. Sci., 11, 769-783, 2007, http://www.hydrol-earth-syst-sci.net/11/769/2007/.

Ma, Y., Tsukamoto, O., Wang, J., Ishikawa, H., and Tamagawa, I.: Analysis of aerodynamic and thermodynamic parameters on the grassy marshland surface of Tibetan Plateau, Prog. Nat. Sci., 12, 36-40, 2002. 
Ma, Y., Fan, S., Ishikawa, H., Tsukamoto, O., Yao, T., Koike, T., Zuo, H., Hu, H., and Su, Z.: Diurnal and inter-monthly variation of land surface heat fluxes over the central Tibetan Plateau area, Theor. Appl. Climatol., 80, 259-273, 2005.

Ma, Y., Menenti, M., Feddes, R., and Wang, J.: Analysis of the land surface heterogeneity and its impact on atmospheric variables and the aerodynamic and thermodynamic roughness lengths, J. Geophys. Res., 113, D08113, doi:10.1029/2007JD009124, 2008.

Mahfouf, J. F. and Noilhan, J.: Comparative study of various formulation of evaporation from bare soil using in situ data, J. Appl. Meteorol., 30, 1354-1365, 1991.

Marht, L. and Ek, M.: The influence of atmospheric stability on potential evaporation, J. Clim. Appl. Meteorol., 23, 222-234, 1984.

Marht, L. and Pan, H.-L.: A two-layer model of soil hydrology, Bound.-Lay. Meteorol., 29, 1-20, 1984.

McCumber, M. C. and Pielke, R. A.: Simulation of the effects of surface fluxes of heat and moisture in a mesoscale numerical model 1. soil layer, J. Geophys. Res., 86, 9929-9938, 1981.

Mitchell, K., Lohmann, D., Houser, P. R., et al.: The multiinstitution North American Land Data Assimilation System (NLDAS): Utilizing multiple GCIP products and partners in a continental distributed hydrological modeling system, J. Geophys. Res., 109, D07S90, doi:10.1029/2003JD003823, 2004.

Pan, H.-L., and Marht, L.: Interaction between soil hydrology and boundary-layer development, Bound.-Lay. Meteorol., 38, 185202, 1987.

Pauwels, V. R. N. and Samson, R.: Comparison of different methods to measure and model actual evapotranspiration rate for a wet sloping grassland, Agr. Water Manage., 82, 1-24, 2006.

Pauwels, V. R. N., Timmermans, W., and Loew, A. Comparison of the estimated water and energy budgets of a large winter wheat field during AgriSAR 2006 by multiple sensors and models, J. Hydrol., 349, 425-440, 2008.

Perez, P. J., Castellvi, F., Ibanez, M., and Rosell, J. I.: Assessment of reliability of Bowen ratio method for partitioning fluxes, Agr. Forest Meteorol., 97, 141-150, 1999.

Peters-Lidard, C. D., Blackburn, E., Liang, X., and Wood, E. F.: The effect of soil thermal conductivity parameterization on surface energy fluxes and temperatures, J. Atmos. Sci., 55, 12091224, 1998.

Rodell, M., Houser, P. R., Jambor, U., Gottschalck, J., Mitchell, K., Meng, C.-J., Arsenault, K., Cosgrove, B., Radakovich, J., Bosilovich, M., Entin, J. K., Walker, J. P., Lohmann, D., and Toll, D.: The Global Land Data Assimilation System, B. Am. Meteorol. Soc., 85(3), 381-394, 2004.
Schaake, J. C., Koren, V. I., Duan, Q.-Y., Mitchell, K., and Chen, F.: Simple water balance model for estimating runoff at different spatial and temporal scales, J. Geophys. Res., 101, 7461-7575, 1996.

Schaake, J., Duan, Q., Andreassian, V., Franks, S., Hall, A., and Leavesley, G.: The model parameter estimation experiment MOPEX, J. Hydrol., 349, 425-440, 2006.

Su, Z., Schmugge, T., Kustas, W. P., and Massman, W. J.: An evaluation of two models for estimation of the roughness length for heat transfer between the land surface and the atmosphere, J. Appl. Meteorol., 40, 1933-1951, 2001.

Sridhar, V., Elliott, R.L., Chen, F., and Brotzge, J. A.: Validation of the Noah-OSU land surface model using surface flux measurements in Oklahoma, J. Geophys. Res., 107(D20), 4418, doi:10.1029/2001JD001306, 2002.

de Vries, D. A.: Thermal properties of soils. Physics of Plant Environments, edited by: van Wijk, W. R., Noord-Holland, 210-235, 1963.

Xue, Y., Sellers, P. J., Kinter, J. L., and Shukla, J.: A simplified biosphere model for global climate studies, J. Climate, 4, 345364, 1991.

Yang, K., Koike, T., Fujii, H., Tamagawa, K., and Hirose, N.: Improvement of surface flux parameterizations with a turbulencerelated length, Q. J. Roy. Meteor. Soc., 128, 2073-2087, 2002.

Yang, K., Koike, T., and Yang, D.: Surface flux parameterization in the Tibetan Plateau, Bound.-Lay. Meteorol., 116, 245-262, 2003.

Yang, K., Koike, T., Ye, B., and Bastidas, L.: Inverse analysis of the role of soil vertical heterogeneity in controlling surface soil state and energy partition, J. Geophys. Res., 110, D08101, doi:10.1029/2004/JD005500, 2005.

Yang, K., Koike, T., Ishikawa, H., Kim, J., Li, X., Liu, H., Liu, S., Ma, Y., and Wang, J.: Turbulent flux transfer over bare-soil surfaces: Characteristics and Parameterizations, J. Appl. Meteorol. Clim., 47, 276-290, 2008.

Zeng, X. and Dickinson, R. E.: Effect of surface sublayer on surface skin temperature and flux, J. Climate, 11, 537-550, 1998.

Zilitinkevich, S. S.: Non-local turbulent transport: Pollution dispersion aspects of coherent structure of convective flow, in: Air Pollution, Vol. 1, Air Pollution Theory and Simulation, edited by: Power, H., Moussiopoulos, N., and Brebbia, C. A., Computational Mechanics Publication, Southampton, 53-60, 1995. 